ENCUESTA 



\section{ENCUESTA SOBRE EL REFERÉNDUM}

\section{PRESENTACIÓN}

Probablemente ninguno de los viejos profesores de la asignatura ha olvidado aún como el entorno del General Franco buscó solventar vía referéndums el que la legitimidad de su poder político estaba huérfano de testar periódicamente su nivel de asentimiento popular en elecciones libres y competitivas. No es preciso recordar que se trató de contados referéndums celebrados en momentos muy espaciados, ayunos de libertad de propaganda a favor del «NO» (opción cuya defensa quedaba ilegalizada) y sin control ni del proceso de votación ni del escrutinio.

Sin entrar a valorar lo anterior, desde la mera observación de nuestro proceso constituyente de 1977/1978, se recuerda que uno de los miembros de la ponencia del Congreso de los Diputados, Manuel Fraga, puso especial ahínco en preveer la posibilidad de múltiples supuestos de celebración de referéndums, que se reflejaron especialmente en el artículo 85 propuesto en el informe de la ponencia.

Cabe igualmente traer a la memoria que al abordarse la deliberación del proyecto de Constitución en la Comisión del Congreso, se formó de facto una «segunda ponencia», entre el 29 de mayo y el 13 de junio, integrada por representantes de los grupos parlamentarios $^{1}$ con la única excepción de Alianza Popular. Entre sus más de diez acuerdos significativos se adoptó el sugerido por el Director de esta revista para constitucionalizar, en forma bien diferente, el Instituto jurídico público del referéndum, lo que se plasmó en el vigente artículo $92 \mathrm{CE}$, que, como bien sabemos, instaura un referéndum consultivo de todos los ciudadanos, a propuesta del Presidente del Gobierno y con autorización previa del Congreso de los Diputados, limitando las posibilidades de convocatoria y constriñendo el campo de aplicación. Consta en el Diario de Sesiones el apoyo a esta fórmula de todos los grupos parlamentarios menos el de Alianza Popular, en cuyo nombre Manuel Fraga tomó la palabra para argumentar su más plena discrepancia.

Mucho más recientemente, cuando el equipo de redacción de Teoría y Realidad Constitucional preparó nuestro número 27, monográfico dedicado a la STC 31/2010 sobre el Estatuto de Autonomía de Cataluña, comentamos de forma reiterada las formas en que el Instituto del Referéndum había estado contemplado bien en el proceso de aprobación

1. Estaba integrada por los siguientes diputados: de UCD (Fernando Abril, Óscar Alzaga, Gabriel Cisneros, José Luis Meilan y José Pedro Pérez-LLorca), PSOE (Alfonso Guerra y Gregorio Peces-Barba), PSC (Eduardo Martín Toval), PCE (Jordí Solé-Tura) y Minoría Catalana (Miguel Roca), a la que en algunas sesiones se sumaron por el PNV Xabier Arzallus y Marcos Vizcaya. 
del mismo, bien en su articulado bajo el rótulo de «consulta popular» y nos llamó la atención que en la muy abundante bibliografía producida por los especialistas de nuestra disciplina la problemática del referéndum en nuestra época estaba lejos de haber sido estudiada con plena profundidad.

Y al planificar nuestro número 29 monográfico sobre la reforma constitucional, volvió a emerger la forma cuestionable en que diversos colectivos sociales y algún partido político pequeño habían enarbolado la bandera del presunto vicio de legitimidad que sufría la reforma del artículo 135 CE por no estar culminada con la celebración de un referéndum.

En suma, los hitos anteriores y algunos otros que hemos procurado ahorrar al sufrido lector, jalonan un itinerario de reflexión que desemboca precisamente en nuestro interés intelectual por cobijar en el presente número una encuesta dirigida a catedráticos de la asignatura, de prestigio cierto. Se trata, en suma, de intentar contribuir a impulsar un debate entre nuestros constitucionalistas sobre el referéndum en la etapa del siglo XXI que constituye el marco en que han de trabajar los iuspublicistas españoles que leen y escriben en estas pequeñas páginas, que siempre permanecerán abiertas a ulteriores reflexiones, dotadas de suficiente rigor académico, sobre esta intrincada materia.

Excusado es decir que a quienes nos honran con sus respuestas se les ha rogado que expongan sus criterios con la máxima libertad, incluso pudiendo tomar algunas de las preguntas como meras escarpias en las que colgar aquello que más les interesa o que les parezca oportuno exponer o defender. Es de justicia mostrar nuestro reconocimiento y gratitud por su esfuerzo y por la calidad de sus contribuciones.

\section{CUESTIONES}

1. ¿Considera adecuado el tratamiento general que la Constitución hace del referéndum? Como sabemos, en el proceso constituyente el informe de la ponencia preveía más supuestos de referéndum de los finalmente incluidos en el texto constitucional. En su opinión, ¿sería necesario algún cambio, bien para ampliar, bien para restringir dichos supuestos?

2. ¿Qué reflexiones le merece el referéndum consultivo establecido en el art. 92 CE? ¿considera adecuado el desarrollo que realizó la LO 2/1980? ¿qué consideraciones nos formularía a la vista de los casos en los que se ha convocado este tipo de referéndum?

3. En relación al referéndum en el proceso de reforma constitucional, ¿quiere hacernos alguna reflexión?

4. En el caso concreto del art. 168 CE ¿le parece correcta la exigencia de referéndum para todos los casos previstos en este artículo? Y ¿qué valoración le merece el procedimiento del art. 168, especialmente teniendo en cuenta que es necesaria la disolución del parlamento, la celebración de elecciones generales, y la constitución de un nuevo parlamento?

5. Rogamos su opinión sobre el referéndum que se exige para la aprobación y reforma de ciertos Estatutos de Autonomía

6. ¿Qué características técnicas considera que debería tener una consulta a los ciudadanos para entender que el resultado de la misma es expresión clara de la voluntad de los mismos y en qué supuestos? ¿ ¿sería necesario para ello exigir un quórum determinado de participación? ¿ sería suficiente una mayoría simple o debería exigirse una mayoría cualificada? 
7. ¿Considera inconstitucional la ley aprobada por el Parlamento de Cataluña Ley 4/2010, de 17 de marzo, de consultas populares por vía de referéndum? En caso afirmativo, ¿por qué motivo?

\section{ENCUESTADOS}

JOSÉ LUIS CASCAJO CASTRO, Catedrático de Derecho Constitucional de la Universidad de Salamanca

ELOY GARCÍA, Catedrático de Derecho Constitucional de la Universidad de Vigo

JOAN OLIVER ARAUJO, Catedrático de Derecho Constitucional de la Universidad de las Islas Baleares

IGNACIO TORRES MURO, Catedrático de Derecho Constitucional de la Universidad Complutense de Madrid

\section{RESPUESTAS}

1. ¿Considera adecuado el tratamiento general que la Constitución hace del referéndum? Como sabemos, en el proceso constituyente el informe de la ponencia preveía más supuestos de referéndum de los finalmente incluidos en el texto constitucional. En su opinión, ¿sería necesario algún cambio, bien para ampliar, bien para restringir dichos supuestos?

\section{JOSE LUIS CASCAJO CASTRO}

Los primeros autores que se ocuparon de esta materia ya señalaron que faltó coordinación a la hora de regular constitucionalmente la figura del Referendum. De manera que si hubo el propósito de recoger en un cuerpo único la totalidad de sus modalidades, el texto constitucional no lo consiguió. En este sentido, habida cuenta además de la experiencia habida desde la entrada en vigor de la Constitución, el Referendum es una de las instituciones que resultan manifiestamente mejorables. Pero para cualquier tipo de cambio en el alcance de la misma se requiere del acuerdo entre las fuerzas políticas, aspecto que no parece de momento de fácil alcance.

Resulta extraña, vista desde hoy, la desconfianza del constituyente hacia los institutos de democracia directa como posibles factores de desestabilización política. La práctica no sólo ha desmentido aquellos falsos temores sino que además ha convertido en pura retórica cualquier cálculo sobre la dosis de participación por via de referéndum que es compatible con nuestro sistema vigente de democracia representativa. Ya va siendo hora de volver a pensar en una opción favorable y abierta de esta Institución tal como apareció en los primeros momentos del proceso constituyente. La tensión entre nuestro sistema político democrático entendido como proceso de participación y el mismo sistema reducido a un mero método de selección de dirigentes está llegando a un nivel difícilmente soportable. 
En este punto el papel del Tribunal Constitucional ha sido más bien condescendiente a la hora de frenar las indeseables derivaciones partidocráticas de la democracia española. Condescendencia que se traduce en un exceso de cautela cuando en la STC 119/95,FJ3, dice que «aun si se admitieran que la Ley puede ampliar los casos de participación directa, los supuestos habrían de ser, en todo caso, excepcionales en un régimen de democracia representativa como el instaurado por nuestra Constitución, en el que priman los mecanismos de democracia representativa sobre los de participación directa».

Sabido es que en el proceso constituyente se eliminó la posibilidad del referéndum abrogativo y no es cuestión ahora de enredarse en propuestas académicas más o menos gratuitas. Ha quedado sin embargo, en mi opinión, una especia de profundo y larvado temor al uso del referéndum en los procesos de reforma constitucional que, de alguna forma, ha paralizado los procesos de cambio. Fue patente, tal como se puede leer en el Diario de Sesiones del proceso de elaboración de la Constitución, la desconfianza de los partidos de izquierda respecto a la eventual actuación del cuerpo electoral en procesos referendarios y premonitoria la postura de Fraga Iribarne en relación con el fenómeno de la partidocracia y su propuesta de que todo cambio constitucional requiere de referéndum. El contexto sociopolítico de la transición sobrevaloró el papel de los partidos políticos y exageró el temor a los instrumentos de democracia directa. Hoy, a la vista de un rampante sistema de partidos que no permite la existencia de espacios públicos sin colonizar, se hace más patente el componente democrático del Referendum, así como su utilidad en los procesos de toma de decisiones colectivas.

Pasados ya más de treinta años, no sobraría una reforma de la LOMR que definiera el régimen jurídico de las consultas políticas por vía de referéndum, realizadas en cualquiera de los posibles ámbitos territoriales. Sobre el tipo de referéndum consultivo autonómico hay ya suficientes criterios jurisprudenciales y doctrinales como para poder orientar al legislador. Entre los requisitos que debería cumplir esta figura, se suele citar: la capacidad de las Comunidades Autónomas para convocar consultas en su ámbito, reflejada competencialmente en su propio Estatuto, el supuesto de que habrán de versar sobre decisiones políticas de especial trascendencia y la autorización del Estado con la doble función de verificación de los citados requisitos y el control político de oportunidad. Sabemos también que el Referendum como materia propia de un título competencial abarca según la STC 103/2008 normas sobre la autorización estatal (permitida o impuesta) y también la determinación de los elementos básicos de su régimen jurídico (condiciones y procedimiento) que por previsión constitucional expresa siguen estando reservados a la ley orgánica reguladora del Referendum. En suma, más que de ampliar o restringir los supuestos de referéndum, constitucionalmente previstos, se trataría de mejorar la regulación jurídica de los mismos.

\section{ELOY GARCÍA}

Antes de aventurar opinión alguna y de sugerir propuestas poco fundamentadas, tal vez fuera aconsejable detenerse a repasar los términos de la relación que media entre referéndum y Constitución, o mejor, entiendo que para evitar incurrir en asunto tan delicado en juicios arbitrarios concebidos a la manera de aquello que Ortega calificaba de 
«ocurrencias», puede resultar muy saludable y esclarecedor comenzar haciendo un esfuerzo por refrescar las claves conceptuales que guían la coexistencia de los institutos de la llamada democracia directa — uno de los cuales es el referéndum — con la idea de poder limitado en cuanto presupuesto nuclear irreductible que informa la noción moderna de Constitución. El proceso de gestación de estos instrumentos en el momento de elaboración de la Constitución de 1978, y la forma en cómo, y por qué, las previsiones iniciales de la ponencia constitucional de incluir en el texto una serie de fórmulas de democracia directa junto a los mecanismos típicos de la representativa, fueron yendo paulatinamente a menos hasta quedar reducidas a la mínima expresión, a algo prácticamente testimonial, en la redacción definitiva, ha sido perfectamente explicado y analizado por Pedro Cruz en un conocido trabajo. De modo que no parece necesario efectuar ahora más referencias al respecto. Por eso, para indagar con un mínimo de provecho cualquier problema relacionado con la operatividad real de estos institutos en nuestro régimen político y sacar de ahí conclusiones en favor o en contra de su extensión o reducción, convendría aproximarse al tema desde una óptica diferente: la que se corresponde con el significado político y constitucional de la democracia directa como principio político, y su difícil incardinación con el —en la teoría tradicional - radicalmente opuesto principio representativo, una cuestión que, hasta dónde se me alcanza, hasta la fecha sólo ha sido estudiada seriamente entre nosotros por la monografía de Luis Aguiar.

Se trata de recapacitar en torno a la funcionalidad operativa de estas figuras destinadas a expresar directamente la voluntad popular desde un doble parámetro que se corresponde, de un lado, con el hecho de que su justificación y explicación lógica se encuadra en el marco de una cierta concepción organizativa — que no filosófica ni ontología- de la democracia, y de otro, con las lecciones que nacen de la experiencia acumulada en treinta y cinco años de vida constitucional española. Ello nos permitirá juzgar con mayor precisión su utilidad instrumental en un tiempo como el que estamos viviendo, al que - y espero no parecer exagerado — se podría calificar de situación límite para el sistema de democracia representativa de partidos.

Así pues, hay que comenzar por estudiar la razón de ser de fondo de las instituciones de democracia directa de las que el referéndum — por sus enormes implicacioneses sin duda la más importante y, además, la principal figura de esta naturaleza recogida en la Constitución. Y para hacerlo conviene situarse en dos planos: uno de encuadramiento histórico-constitucional y otro de ideas y concepciones políticas.

Desde la perspectiva de la historia constitucional moderna tres son los momentos en que las instituciones de democracia directa irrumpen como procedimientos propios del Estado Constitucional, el primero discurre entre los años de la experiencia revolucionaria francesa. El segundo y el tercero en el contexto de la praxis constitucional norteamericana.

En Francia tanto, inicialmente, la Constitución jacobina del año I, como luego, más tarde, la usurpación bonapartista, recurren a instituciones de democracia directa con resultados nada edificantes. En el primer caso porque las complicadas previsiones de la Constitución de 1793 nunca llegaron a entrar en vigor y desde el principio fueron sustituidas por el Terror y la dictadura. En el segundo porque, como repite machaconamente Loewenstein, en realidad se trataba sólo de una colección de métodos demagógicos ideados ex profeso para manipular la voluntad democrática y no destinada a garantizar su 
natural expresión. Estamos de lleno ante experiencias que forman parte de lo que Friedrich calificaba de patologías de la política que han dejado en la memoria del constitucionalismo europeo un difuminado sentimiento de resquemor y prevención hacia unos mecanismos de democracia directa que fácilmente pueden ser utilizados como fórmulas de encubrimiento de la ilegitimidad política.

La otra experiencia que en los instantes iniciales del constitucionalismo moderno acude históricamente a este tipo de institutos, es la norteamericana que se fragua en el curso de la Revolución que trajo consigo la ruptura con la Corona inglesa. Y en la que si bien es cierto que estas figuras no tienen cabida en la Constitución federal de los Estados Unidos redactada tras la Independencia, si estarán presentes, en cambio, de manera notoria en las constituciones de los estados particulares que integran la Unión, donde adquirirán una cierta importancia y eficacia operativa en dos planos. Se trata, por un lado, del referéndum de ratificación que sigue a la acción de las convenciones constituyentes de las viejas colonias que en razón a la Independencia procederán a auto-refundarse como estados de la Unión. En este caso, como recuerda Laboulaye, el referéndum opera no como la encarnación única del Poder Constituyente, sino como órgano o instancia de un obrar soberano que se expresa como elemento o fase de un acto complejo. No hay Constitución y se trata de elaborarla, por eso se pone en marcha un proceso constituyente en el que interviene varios actores y muy especialmente el pueblo en primera persona. El referéndum es aquí una expresión de soberanía, no la única, pero sí se inserta en la lógica de la soberanía popular. Aunque insisto no es el único acto del constituyente ya que sin la intervención de la convención el pronunciamiento momentáneo del pueblo en un referéndum no permitiría construir nada, no seviría para dar estabilidad a la Política, la gran misión de la Constitución de los Modernos.

Pero en segundo lugar, en América aparece también la tercera forma de entender el referéndum y en general las instituciones de democracia directa. La que podríamos definir como lectura constitucional del referéndum, que supone definirlo como un poder legal, constituido, encerrado en el contexto de la legalidad constitucional y cuya misión y funcionalidad se explica como formas de contrapeso, de contra-equilibrio, insertas en aquello que se conoce como sistema de chekcs and balances. Es decir, y aquí estriba la clave de toda nuestra argumentación, la concepción norteamericana más que asignar a semejantes mecanismos la misión de construir, definir y expresar una voluntad popular concreta aplicable de forma inexorable, función que sustancialmente quedará en manos de los órganos de representación, les atribuye una doble misión de contrapeso, de una parte, de tipo claramente negativo, consistente en el control, la supervisión, la contradicción en la acción de los demás órganos y tendente al conflicto con ellos, y de otra de naturaleza potencialmente positiva, encaminada a favorecer el desbloqueo de las relaciones entre órganos que están llamados a conformar la voluntad política pública. De lo que se trata pues, no es tanto de que las instituciones de democracia directa contribuyan a construir una determinada opinión y a conformar la voluntad política del Estado, como que en el contexto de la idea de división de poderes, coadyuven bien a controlar y a compensar el proceso por el que discurre la decisión colectiva, bien a permitir que ésta se forme, se manifieste, que la producción de la voluntad llegue a buen fin, cuando los órganos que deben construirla se encuentren bloqueado por conflictos o intereses manifiestamente irreductibles. Lo que, en resumidas cuentas, importa de las mal llamadas figuras de de- 
mocracia directa al constitucionalismo norteamericano, es que sirven tanto para evitar el dominio del uno sobre los muchos, como para mantener operativos y en marcha, los complejos mecanismos representativos al margen de posibles interferencias expúreas. Y esa es una atribución perfectamente constitucional, en el sentido de que tiene lugar en el estricto ámbito de la Constitución, esto es, que se mueve dentro de las fronteras y límites de la Constitución, y que es ejercida en todo caso por un poder que Tocqueville definirá como constituido, y que nunca se postulara como expresión de la soberanía, ya que ni siquiera suele aparecer como trámite habitual en el iter ordinario de construcción de la voluntad política. En el mejor de los ejemplos sólo se expresa como un proceder o paso más, de carácter potestativo, que únicamente se llega a poner en marcha cuando se producen bloqueos. Y ello porque, tras lo que Wood llamó el fin de la Política clásica, también en los Estados Unidos, el pueblo, aun cuando actúa de manera directa, lo hace siempre como poder previsto y derivado de la Constitución. Lo directo o inmediato de su intervención, consiguientemente no prejuzga el valor de su contenido, ni le confiere una significación política diferente, ni otorga a su acción fuerza o valor supraconstitucional.

Y todo esto se aprecia ya muy bien en la era de la Democracia Jacksoniana, en la década de 1830/1840, cuando la preocupación por controlar a la élite que desde la independencia ocupaba el poder y los órganos de la representación, se extendió por todo el país y generó como respuesta la aparición de numerosas instituciones y formas de participación directa.

Y lo mismo cabe repetir poco más o menos, del caso Suizo. Como muy bien razona Giorgio Lombardi, el constitucionalismo y la democracia helvéticos no proceden de una larga línea de continuidad evolutiva que hunde sus raíces en el mundo medieval, sino que arranca de la profunda quiebra que coincide con la guerra civil de $1847 \mathrm{y}$ del postrero compromiso en que se resuelve conciliar los principios de unidad y territorialidad, los cantones con el federalismo de la impropiamente bautizada como Confederación. En este sistema de delicados equilibrios, la Constitución de 1848 y también las constituciones de los cantones, conceden un importante papel de contrapeso de las instancias ordinarias de representación a los mecanismos de participación directa de un pueblo que no deja de ser poder constituido, ni se configuran fundamentalmente como modos procesales que expresan la voluntad del pueblo sino como mecanismos de contrapeso. E institutos como el Landsgemeinde (por cierto en franco retroceso tras haber sido abolido en varios cantones en los últimos veinte años) no son sino piezas arqueológicas de museo sin significación real ninguna para sostener un razonamiento de carácter general sobre la democracia.

Pero, quizás donde mejor se observe toda esta operatividad y funcionalidad de control de las instituciones de democracia directa en el marco del equilibrio constitucional de poderes, es en el texto de la Constitución de Weimar. Como es sabido fue Max Weber, por mediación de Hugo Preus, quien influyo para que la Constitución alemana de 1919 incorporara una serie de mecanismos de democracia directa entre los que se contaban el referéndum y la iniciativa legislativa popular. La razón de ello está clara en los escritos de última hora de Weber: el deseo de contraequilibrar el poder de los partidos, o de manera más precisa, el afán por impedir que las burocracias de los partidos — que conocía y temía desde su temprana lectura de los trabajos de Bryce y Ostrogosky - secaran la fuente democrática en la vida política e impidieran el juego de la renovación e innovación política. Su principal propósito al exigir la presencia de estas instituciones en la 
Constitución de Weimar, era defender un equilibrio democrático del poder, asegurar la existencia de ciertos contrapesos a un Parlamento dominado por partidos burocratizados que pudieran incurrir en políticas de bloqueo. Pero su preocupación principal no le eximía de una cierta ambigüedad y silencio respecto del nuevo significado de estas instituciones en clave de legitimidad política.

Desde esta ambigüedad weberiana construirá justamente, Carl Schmitt su famosa y distorsionante dicotomía Democracia de la identidad/ Democracia de la representación. En varios trabajos anteriores y posteriores, pero muy especialmente en su recensión crítica al concepto de democracia de Thoma ( «el concepto de democracia moderna y su relación con el Estado» de 1924) y en sus Fundamentos del Parlamentarismo pretenderá construir un concepto cualitativamente diferente de la democracia que tiene su último responsable en Rousseau y que se configura en términos políticos a imagen y semejanza de la Ciudad de los Antiguos. Seguramente no es este el lugar apropiado para explicar que tamaña categorización oculta una manipulación artera de la famosa distinción de Benjamín Constant entre Libertad de los Antiguos y Libertad de los Modernos (una deuda más de las muchas que el autor alemán tiene contraídas con Constant y a las que convendrá en su momento prestar atención), sin embargo si lo es y mucho, para insistir en que convirtiendo la democracia participativa en una categorización ontológicamente diferente de la representativa Schmitt procede a efectuar una radical transformación de fondo en la significación de sus mecanismos concretos, a veces difícilmente apreciable a primera vista. De instrumentos de la división de poderes limitados por la Constitución, las instancias de la democracia directa pasan a ser expresión de la misma voluntad soberana que construye la Constitución, y a situarse, por consiguiente, a su mismo nivel. La democracia de la identidad se configura por tanto, como la manifestación de un modelo de democracia ontológicamente superior y más elevada que la propiamente representativa. Es el resultado de la Identidad gobernante-gobernado.

Todo esto concuerda muy bien con las tesis antipluralistas de Schmitt, pero resulta completamente incompatible con la idea de democracia propia de las sociedades actuales donde el acentuado pluralismo y la fuerte heterogeneidad - y hasta fragmentaciónpolítica y social imponen la búsqueda de consensos como primera e indispensable tarea de la política. Y es que allí dónde hay una mínima homogeneidad social, no existe, no puede haber sitio para una democracia de la identidad en el sentido schmittiano de la expresión. Por eso la afirmación de que la democracia directa permite la identidad entre decisión política y sociedad es una falacia que nunca estuvo realmente en la mente de Rousseau. Rousseau, como nos ha enseñado Judith Shklar, era un humanista republicano que pensaba en clave de democracia republicana. El mismo modelo político que Benjamin Constant declaró superado y definitivamente finiquitado cuando escribió acerca de la imposibilidad de instaurar una República en un gran país (1803), y que Schmitt pretendió rescatar en plena República de Weimar para justificar y presentar como nueva legitimidad lo que no era más que una dictadura.

Ahora bien, más que refutar a un Schmitt que ha sido repudiado ya por la historia, en lo que importa insistir aquí es en los perversos y perjudiciales efectos que la persistencia de su inadmisible dicotomía está teniendo en nuestra interpretación del significado y valor de los mecanismos de democracia directa. Y es que son muchos los autores - empezando por Ernest Fraemkel en su trabajo La componente representativa y plebiscitaria del Es- 
tado Constitucional Democratico (1958)— que manejando y repitiendo inconscientemente su conceptualización, hacen de instituciones como el referéndum una figura democrática políticamente superior a los mecanismos representativos, un poder prácticamente constituyente, olvidando que en la democracia constitucional hasta los poderes más democráticos son siempre forzosamente poderes constituidos. Afirmar lo contrario supone, además, entrar en una dinámica destructora de la esencia última de la democracia contemporánea basada en la suma de consensos y aniquiladora de la idea de Constitución como expresión de la limitación del poder.

Por eso resulta muy importante conectar el encuadramiento histórico en el que surgen y cobran vida las figuras de democracia directa, con sus razones de fondo que explican su ser en las democracias pluralistas, ya que sólo se pueden construir los grandes consensos de los que están necesitadas las sociedades contemporáneas acudiendo a los mecanismos representativos. Apelar a la democracia de la identidad en la línea de la argumentación de Schmitt, supone desconocer cómo se forma la voluntad en el Estado Constitucional democrático, y lleva a ignorar el verdadero papel de estas instituciones en cuanto procedimientos de control y contrapeso que tienden a favorecer indirectamente el funcionamiento de la democracia representativa, la única que en realidad cabe en el Estado Constitucional para hacer de la pluralidad social una realidad de expresión única.

En este sentido, nuestra Constitución de 1978 vista desde la óptica de la relación entre mecanismos de participación y representación, resulta perfectamente equiparable a las de las democracias representativas que nos rodean. Tal vez lo único reprochable sería y estamos hablando solamente en un plano institucional acrónico, es decir, sin enjuiciar el juego que en su funcionamiento práctico han venido dando las instituciones - el escaso número y débil fuerza y pequeña influencia operativa de las existentes. Pero lo cierto es que esto tiene más que ver con el contrapeso que tienen atribuidos estos institutos con relación a los mecanismos de la representación.

Como es sabido, la gran preocupación del constituyente español a este respecto, fue reforzar los esquemas y mecanismos representativos de entre los cuales lo más importante es todo aquello que procura un correcto funcionamiento de los partidos políticos. El verdadero centro de gravedad de la democracia constitucional pluralista prevista en la Constitución de 1978 son los partidos que expresan y reducen a actos unitarios, la voluntad de una sociedad heterogénea, operando a través de los mecanismos representativos. A su lado los instrumentos de democracia directa, no son sino contrabalances que asumen mayor protagonismo en la medida en que los partidos ejercen peor su misión, pero siempre con el propósito en el horizonte de equilibrarlos y de ayudarles a cumplir su cometido irremplazable. Así pues, a peor funcionamiento de los partidos mayor y más será el juego de la democracia directa, aunque sólo sea al objeto de posibilitar que la preeminencia de la representación se restablezca, e insisto, nunca para remplazarla porque en nuestro sistema simplemente no es posible. Eso fue sencillamente lo que sucedió en Italia a fines de los años sesenta y principios de los setenta del siglo pasado, cuando la expansión de los referéndums abrogatorios corrió paralela al declive de las ideologías y de los partidos.

Y aquí radica precisamente el problema, porque si bien en una situación normal el papel de las instancias de democracia es ayudar a que se repongan los mecanismos de representación, cuando los daños son irrecuperables pueden terminar abriendo puertas a un 
encubrimiento del poder que culmine en aventuras plebiscitarias del estilo de las que nos describe Marx en ese espléndido ensayo de derecho constitucional que es el 18 de Brumario de Luis Bonaparte (por cierto, todo un estudio de derecho constitucional injustamente olvidado).

Para conjurar el peligro de la utilización demagógica del referéndum contra la Constitución, (recuérdense las palabras de Louis Napoleón: «je n'étais sorti de la légalité que poru rentrer dans le droit. Plus de sept millions de suffrages viennent de m'absoudre en justificant un acte») el mejor y me atrevería a decir que recurso pasa por reforzar los partidos políticos y recomponer sus esquemas democráticos de funcionamientos. Y se refuerza a los partidos, asociándolos férreamente con una serie de muy variados intereses que aparecen vinculados a ciertas ideas políticas, expresadas en forma de diferentes opciones en forma de políticas públicas. Se consigue recomponer sus esquemas democráticos cuando el conflicto por defender su idea prevalece sobre la simple preocupación por asegurar la dominación. Pero la crisis de las ideologías ha afectado muy de lleno a los partidos porque ellas eran la corriente que a modo de torrente sanguíneo distribuía por toda la organización la suma de ideas e intereses que servía para agrupar el partido. Hoy los partidos parecen meras carcasas internamente vacías que compiten entre sí, no por imponer está o aquella política sino únicamente por conquistar, o retener el poder, y en nada ayuda a regenerarlos las luchas que sostienen por el simple dominio de las instituciones del Estado. Se requiere reforzar la democracia representativa, convenciendo a sus auténticos agentes para que recuperen su actividad y protagonismo como instrumentos de acción política. Necesitamos reforzar los partidos y recomponerlos entorno a ideas verdaderamente políticas que movilicen al electorado y le lleven a participar en la vida pública de un gran país — en el sentido de Constant - porque de otra forma todo estará perdido. Las instituciones de democracia directa poco pueden hacer al respecto, porque su misión es contraponerse a un modelo democrático-representativo que está anémico. Una institución de democracia directa nada puede añadir al reforzamiento de una participación cívica que no puede quedar limitada a un simple instante participativo sino que tiene que ser estructurada en el largo plazo y con carácter permanente, que debe consistir en una intervención activa y no reducirse a manifestarse de cuando en cuando en forma de un sí o un no. En pocas palabras, restaurar la ciudadanía activa pasa hoy como ayer por recuperar las ideas que motivan a los hombres a actuar directamente en política tanto en los partidos o instancias sociales, como en las instituciones políticas, porque como decía Alain— «sea cual sea la Constitución, desde el momento en que los hombres se dejan gobernar todo estará dicho».

Pero incluso más, los mecanismos de democracia directa, en este estado de general atonía y alejamiento de la representación democrática en que vivimos sumidos, corren el peligro de ser usados demagógicamente en sociedades que al estar dando la espalda a la política, son susceptibles de conceder cancha a la peor de las manipulaciones, la que proviene de los primeros tiempos del constitucionalismo democrático. En suma pues, reforzar o poner las esperanzas de la renovación democrática en los mecanismos de democracia directa como el referéndum, en un momento que no tiene frente a sí el contrapeso de los partidos que expresan la democracia representativa, equivale a abrir un portillo a la demagogia en medio de un peligroso vacío político. Una sociedad desconcertada se aferra fácilmente a figuras de representación que parecen depararle una sencilla oportunidad 
de manifestar su parecer. Pero si estas no pueden construir una voluntad aceptable para la inmensa mayoría que requiere de muchos consensos, entonces queda expedito el camino para las soluciones demagógicas que destruyen la democracia so pretexto de reforzarla. No me parece que este sea el momento de abrir puertas a una posible democracia plebiscitaria que nada tiene que ver con la idea de ciudadanía activa que desde el fin de la II Guerra Mundial se ha venido encauzando muy aceptablemente en Europa a través de la participación en los partidos y, por mediación de ellos, en las instancias representativas electivas. Es imprescindible en resumen, regenerar y reforzar los partidos.

\section{JOAN OLIVER ARAUJO}

La Constitución Española de 1978, tras varios debates parlamentarios de alto nivel, consagró diversos tipos de referéndums: dos de reforma constitucional, uno consultivo, cuatro autonómicos y uno municipal. Sin embargo, esta pluralidad de referéndums es bastante engañosa, y no debe llevarnos a pensar que el mecanismo de las consultas populares directas tiene asignado un papel importante en nuestro sistema político. Por el contrario, a lo largo del proceso constituyente se fue haciendo cada vez más patente que, en los principales partidos políticos, existía una notable dosis de desconfianza hacia los instrumentos de participación directa en general, y hacia el referéndum en particular. El resultado ha sido que en el Texto Constitucional definitivo el referéndum ha aparecido sensiblemente devaluado en todos los sentidos, lo que, en principio, no parece muy de acuerdo con los amplios términos con que el artículo 23 CE consagra el derecho a participar directamente en los asuntos públicos (en el mismo sentido se expresa el profesor Aguiar de Luque).

Los aspectos en los que, durante el iter constituyente, se concretó la referida desconfianza hacia las consultas populares fueron básicamente tres: la supresión del referéndum legislativo de ratificación y del referéndum legislativo abrogatorio, la restricción de los sujetos legitimados para solicitar la celebración de un referéndum, y la calificación de «consultivo» al referéndum sobre decisiones políticas de especial trascendencia. Veamos brevemente qué argumentos se utilizaron, en sede parlamentaria, para cercenar la fuerza de este instrumento de democracia directa.

1) Supresión del referéndum legislativo de ratificación y del referéndum legislativo abrogatorio. Lo más destacado del último proceso constituyente en lo que afecta a la institución del referéndum fue, sin ninguna duda, la supresión del referéndum legislativo de ratificación y del referéndum legislativo abrogatorio, modalidades que, amén de gozar de cierta tradición en el Derecho comparado, cuentan con algunos precedentes en el Derecho histórico español. En efecto, tanto en el Anteproyecto de Constitución (BOC 5-I-1978) como en el Informe de la Ponencia (BOC 17-IV-1978), el artículo que se corresponde con el número 92 del texto definitivo recogía tres clases de referéndums: sobre leyes aprobadas por las Cortes y aún no sancionadas, sobre decisiones políticas de especial trascendencia y sobre leyes en vigor. Sin embargo, al llegar a la Comisión de Asuntos Constitucionales del Congreso, la institución del referéndum sufrió una drástica restricción, fruto de una enmienda in voce del profesor Jordi Solé Tura (PCE-PSUC) consensuada entre todos los Grupos Parlamentarios a excepción del de Alianza Popular. El profesor Solé Tura al 
defender dicha enmienda, por la que se suprimían las dos modalidades de referéndum legislativo (el de ratificación y el abrogatorio), inició un interesante y denso debate que se prolongaría hasta el Pleno del Congreso de los Diputados. A su juicio, el referéndum sobre leyes aprobadas por las Cortes y aún no sancionadas «abre una extraña posibilidad de que la soberanía del Parlamento sea absolutamente menoscabada y establece, sobre todo, la posibilidad de conflictos muy serios entre Gobierno, Rey y Parlamento, puesto que se trata de leyes que ya han sido aprobadas pero que antes de ser sancionadas pueden ser sometidas a referéndum». Por lo que se refiere al referéndum abrogatorio, el diputado de UCD José Pedro Pérez-Llorca, al intervenir para apoyar la enmienda, afirmó que es una técnica que "plantea problemas similares, cuando no más delicados» que el referéndum legislativo de ratificación. En su opinión - expresando un temor que ya había puesto de relieve el diputado socialista Cordero en las Cortes Constituyentes de la Segunda República - el referéndum abrogatorio era nocivo para la estabilidad y el «armónico desarrollo» del sistema político, especialmente en el momento en que el Parlamento debía aprobar las leyes complementarias de la Constitución. En turno en contra, intervino el profesor Manuel Fraga Iribarne (AP) para mostrar su total disconformidad con estas supresiones, pues a su juicio el referéndum es una ventana abierta a la participación de las fuerzas sociales en la vida política sin tener que pasar por el tamiz de los partidos políticos, evitando caer en la dañina «partitocracia». A esta última objeción, el profesor Solé Tura replicó diciendo que, en un país donde precisamente los partidos políticos han estado prohibidos durante cuarenta años, contemplar o denunciar el peligro de la partitocracia «es un mal servicio a la causa de la consolidación de la democracia que intentamos llevar adelante». Y añadió: "Aquí el problema que tenemos hoy no es el de la partitocracia, sino conseguir que los partidos funcionen, conseguir que los partidos sean representativos, que los partidos tengan fuerza, que los partidos sean reconocidos como intérpretes concretos de las grandes masas de la población, y eso es lo fundamental». Sometida a votación, la enmienda fue aprobada por treinta y tres votos a favor y dos en contra (curiosamente de los diputados Manuel Fraga — AP — y Heribert Barrera - ERC — ), sin abstenciones. En consecuencia, el primer apartado del entonces artículo 86, tras las indicadas amputaciones, quedaría — con redacción que ya iba a ser definitiva- con el siguiente tenor: «Las decisiones políticas de especial trascendencia podrán ser sometidas a referéndum consultivo de todos los ciudadanos» (BOC 1-VII-1978). En el Pleno del Congreso de los Diputados, se reprodujo el debate en términos muy similares, como consecuencia de la propuesta del profesor Fraga Iribarne de volver al texto de la Ponencia. Por 243 votos contra 16 dicha pretensión fue rechazada.

2) Restricción de los sujetos legitimados para solicitar la celebración de un referéndum. En los tres primeros textos del iter constituyente, la legitimación para pedir la convocatoria de alguno de los tres tipos de referéndums facultativos reconocidos en el entonces artículo 85 (esto es, el legislativo de ratificación, sobre decisiones políticas de especial trascendencia y el legislativo abrogatorio) estaba atribuida a una pluralidad de sujetos. Así, en el Borrador de Constitución, divulgado por la prensa en noviembre de 1977, la legitimación se otorgaba — en todas las modalidades de referéndums - al Gobierno, al Congreso, al Senado, a tres Asambleas Regionales y a 500.000 electores. En el Anteproyecto de Constitución, publicado en el BOC el 5 de enero de 1978, se confería dicha iniciativa al Congreso, al Senado y a tres Asambleas de Territorios Autónomos en las tres clases de re- 
feréndums, y a 750.000 electores en el supuesto del referéndum legislativo abrogatorio. La Ponencia en su Informe (BOC 17-IV-1978), tras reestructurar el precepto con la oposición de UCD, legitimaba, en todos los supuestos, al Gobierno, al Congreso y al Senado, y, para convocar referéndums abrogatorios, a tres Comunidades Autónomas y a los electores en número no inferior a 750.000. Aunque, en estas primeras fases del proceso constituyente, ya se apreciaba una tendencia progresivamente restrictiva en el tema de la iniciativa de los referéndums y aunque algunas de las enmiendas formuladas al artículo 85 acentuaban notablemente esta impresión, lo cierto es que «ninguna de ellas hacía presentir la drástica cirugía» a la que dicho artículo sería sometido en la Comisión de Asuntos Constitucionales del Congreso (Cruz Villalón). En efecto, al ser aprobada la enmienda in voce presentada por el profesor Solé Tura, a la que ya nos hemos referido, la facultad de solicitar la celebración de una consulta popular quedó restringida exclusivamente al Presidente del Gobierno. Lo más llamativo — y posiblemente discutible — de este proceso restrictivo es la supresión de la iniciativa popular para exigir la celebración de un referéndum. Los argumentos de Heribert Barrera en el Pleno del Congreso de los Diputados oponiéndose a esta exclusión nos parecen especialmente sólidos. A su juicio, el que un determinado número de ciudadanos pudiera pedir la convocatoria de un referéndum evitaría «un posible divorcio entre la clase política y el país». Y añadía: «Los partidos son sin duda instrumentos indispensables de la democracia, pero la oligarquía de los partidos o de los estados mayores de los partidos... me parece no solamente injusta, sino peligrosa para el futuro de la democracia, sobre todo si esto va acompañado de sistemas electorales que eliminan también, en gran parte, el contacto directo» con los representantes. José Pedro Pérez-Llorca, con argumentos mucho más pragmáticos, justificaba la supresión de la iniciativa popular para demandar un referéndum afirmando que esta facultad otorgaría a los grupos minoritarios, e incluso extraparlamentarios, un poder extraordinario que podría «crear conflictos graves al funcionamiento adecuado del sistema».

3) Calificación de «consultivo» al referéndum sobre decisiones políticas de especial trascendencia. La citada enmienda in voce del profesor Solé Tura, además de suprimir las dos modalidades de referéndum legislativo y de restringir al Presidente del Gobierno la facultad de solicitar su convocatoria, calificó de «consultivo» al referéndum sobre «decisiones políticas de especial trascendencia». No vamos a analizar ahora el significado y el alcance jurídico-político de la agregación de este adjetivo, tema que comentaremos al contestar a la segunda pregunta de este cuestionario. Lo que sí debemos destacar en este momento es que el propósito de los constituyentes al introducirlo fue, sin ninguna duda, el de recortar la eficacia decisoria de este mecanismo de participación directa.

De cuanto antecede se deduce claramente que bajo esta polémica, que aquí no hemos hecho más que apuntar, subyacía el problema de determinar en qué medida los mecanismos de participación directa debían «sobresalir en el juego político o ser meros correctores de la democracia representativa» (Alzaga Villaamil). Este giro radical que experimentó la institución del referéndum en la Comisión de Asuntos Constitucionales del Congreso — similar al que había experimentado, en el mismo trámite, la regulación de la iniciativa popular - responde, como afirma certeramente el profesor Santamaría Pastor, «a la asunción decidida de una opción política nítida, consistente en el reforzamiento de los mecanismos de la democracia representativa». Y añade: «Frente a una pri- 
mera postura, un tanto ingenua, de democratización a ultranza, los constituyentes apreciaron con toda claridad los peligros de un posible abuso de la apellatio ad populum». Las causas principales de este giro espectacular, apoyado por todos los partidos políticos a excepción de Alianza Popular, fueron — a juicio de la doctrina- básicamente cuatro: el recuerdo inmediato de las connotaciones autoritarias y antipartidistas del referéndum en el régimen franquista, la polémica experiencia italiana del referéndum abrogatorio, la repetida utilización del referéndum en los primeros años de la V República Francesa con fines carismáticos, y la imperiosa necesidad de fortalecer y potenciar los partidos políticos en España tras cuatro décadas de estar prohibidos.

Los redactores de la Constitución Española, muy influidos por los cuatro temas que acabamos de indicar, regularon el referéndum con un espíritu marcadamente restrictivo, lo que ha conducido a «descafeinar» en buena medida dicha institución (Alzaga Villaamil). Es indiscutible que en los primeros textos del iter constituyente las diversas modalidades de referéndum aparecían reguladas de «forma torpe e inconveniente», siendo susceptibles de engendrar problemas muy graves para el correcto funcionamiento del sistema (Torres del Moral). Pero los constituyentes, en lugar de intentar evitar los riesgos mejorando su regulación, optaron por suprimir los dos tipos de referéndums que más poder conferían a los ciudadanos y por restringir muy sensiblemente el referéndum sobre decisiones políticas. Como afirmó el profesor Tomás Villarroya, «si en otros tiempos o lugares se usó indebidamente del referéndum legislativo, lo pertinente no es suprimirlo, sino depurarlo y rescatarlo para la democracia. Pero, además — seguía diciendo el profesor de Valencia-, la democracia representativa, entre nosotros - y en otros lugares - aparece, en buena medida, expropiada por los partidos políticos: justo es que, en determinadas ocasiones, se conceda al pueblo la posibilidad de expresar directamente su voluntad». Parafraseando a mi maestro, el profesor Luis López Guerra, podríamos decir que es necesario introducir nuevos instrumentos que pongan al día (y quizás mejoren) el modelo constitucional inicial. En efecto, no cabe desconocer que las circunstancias que se daban durante el proceso constituyente (de recién salida de una larga dictadura y débil implantación de la democracia) han cambiado radicalmente en la actualidad (de dilatada vigencia del sistema constitucional y poder absoluto de los partidos políticos), lo que haría muy aconsejable prescindir de algunas de las cautelas que se adoptaron en el Texto Constitucional aprobado en 1978. A mi juicio, es imprescindible — para vivificar nuestra mortecina democracia- incorporar efectivamente a nuestro sistema constitucional diversos elementos de democracia directa con fuerza vinculante y, entre ellos y de manera muy especial, el referéndum. Si periódicamente se sometieran a la consideración de los ciudadanos las cuestiones más polémicas que se fueran suscitando en la vida pública, se limitaría el —insufrible - poder omnímodo de las oligarquías de los partidos y se daría a los ciudadanos más capacidad de decisión política (menos de la que tienen ahora es casi imposible), revitalizando el papel protagonista que les corresponde en una democracia avanzada y creíble.

1 Véase, por todos, la síntesis que hace LÓPEZ GONZÁLEZ en El referéndum en el sistema español de participación política, UPV, Valencia, 2005, págs. 39 y ss. 


\section{IGNACIO TORRES MURO}

Como es bien sabido el texto de nuestra norma suprema es, en general, cicatero con el referéndum, en una decisión (ahí están los debates al respecto) que tenía como objetivo el reforzamiento de los partidos políticos como el cauce normal de participación política. Tampoco descubro nada si digo que existía un prejuicio claro, por parte sobre todo de la izquierda, contra las instituciones de democracia directa como instrumento de sistemas autoritarios o semiautoritarios, basado en las experiencias propias (plebiscitos franquistas) y ajenas (para aquellos que se mostraban críticos con el régimen gaullista).

Recuérdese que la decisión de limitar significativamente los supuestos en los que eran posibles los referendos, dentro del procedimiento legislativo, o abrogatorios, fue resultado de las argumentaciones del diputado comunista Solé Tura, rápidamente apoyado por los representantes de la Unión de Centro Democrático, mientras que los que se situaban a la derecha de ésta, como Manuel Fraga, de Alianza Popular, se mostraron muy críticos con estos recortes ${ }^{1}$.

Resulta curioso ver como han evolucionado las posiciones de la extrema izquierda. De una defensa numantina de los partidos, y los sindicatos, como instrumentos de mediación política, tal y como defendía el PCE-PSUC en el proceso constituyente, a la apertura a soluciones mucho más tolerantes con los instrumentos de democracia directa, o participativa, como alternativa a la representativa clásica, que caracteriza los últimos pronunciamientos de Izquierda Unida al respecto. No se puede negar que el cambio tenga mucho que ver con las diferencias entre las respectivas situaciones, una de consolidación de una democracia naciente, y otra de intentos de ir más allá en el funcionamiento de una ya consolidada, y que presenta síntomas claros de cansancio en las instituciones. No deja por ello de ser significativo.

A mi juicio la manera constituyente de ver las cosas, restrictiva con los referendos, tiene bastante fundamento político, y constitucional. Nunca he creído en la democracia directa, no digamos ya en la asamblearia, como alternativa seria a la democracia representativa, y considero que la articulación correcta de los procesos referendarios es muy complicada, tanto por la necesidad de reducir las alternativas para el votante a unas pocas, normalmente dos, como por lo difícil que resulta que temas tan importantes como la campaña previa a los mismos se lleven con el necesario equilibrio.

Comparto, por ello, los prejuicios de cierta doctrina de países muy respetables, y con una larga experiencia democrática, como el Reino Unido, hacia los experimentos de este tipo, que, en mi manera de ver las cosas, solamente pueden aportar soluciones en casos muy concretos. Se me antojan, además, claramente fantasiosas las propuestas de tener a los ciudadanos participando continuamente mediante medios telemáticos. Se olvida así el carácter ceremonial, y excepcional, que deben mantener los procesos de participación política, que no pueden ser cosa de todos los días, o de excesiva frecuencia, pues los ciudadanos tienen cosas mejores en las que ocupar su tiempo.

Poner al pueblo soberano ante el dilema de pronunciarse, con un sí o un no, sobre temas habitualmente muy complejos, que no pueden plantearse con soluciones simplistas, y que requieren de debates en profundidad, que no es posible abordar en una campaña normalmente sumaria, y poco profunda, me parece un error. Se me dirá que eso es lo que estamos haciendo continuamente con los mecanismos de representación, también los de la democracia más clásica, pero en estos últimos no se nos pide una decisión sobre 
una materia imposible de simplificar, sino que depositemos nuestra confianza en un equipo de personas que nos proponen un programa electoral con muy diversos aspectos, pero que podemos analizar con mayor o menor detenimiento, sí no es que, dada la calidad habitual en nuestros sistemas democráticos, acabamos decidiendo con las entrañas más que con el cerebro.

En principio, prefiero, además, que los políticos, acostumbrados, en un modelo ideal, a responder de sus decisiones y, lo que es también importante, a administrar todo lo que traen consigo las mismas, sean estas en un sentido o en otro, sustituyan a un electorado por definición irresponsable, que no se enfrenta a la necesidad de trabajar día a día con unos acuerdos tomados de una manera en exceso sumaria. Es este un dato importantísimo, pues es preferible que decida quien va a asumir las consecuencias de sus actos, ya que esto tendrá sin duda como efecto que ponderará más adecuadamente las ventajas, y los inconvenientes. No quiero con esto decir que el pueblo no tenga nunca en cuenta, de una manera infantil, lo que puede derivarse de sus decisiones en los referendos, pero sí que su relación con las que toma es diferente de la que tienen, por definición, sus representantes.

Dicho esto, por supuesto que es posible concebir excepciones a la regla, y, por eso, el tratamiento que de los referendos se hace en el texto constitucional español me parece, en líneas generales, correcto: una desconfianza de principio mitigada por algunas concesiones ineludibles. Ello no obsta para que crea que son posibles numerosas críticas a aspectos concretos. Se trata de una regulación acorde con el Estado de partidos, y el sistema de democracia fundamentalmente representativa, que adoptaron finalmente nuestros constituyentes, por muy buenas razones que considero que siguen teniendo una cierta vigencia, aún cuando la deriva "partidocrática» en la que vivimos nos lleve, en algunos momentos, a cuestionarlas.

Este último asunto debiera ser la principal preocupación de nuestros servidores públicos, y de los cultivadores del derecho constitucional. Es a partir de lo que se puede considerar como el mal funcionamiento, ya que no fracaso sin paliativos, de nuestra democracia representativa, cuando por determinados actores políticos, apoyados en ciertas corrientes de pensamiento críticas con la democracia liberal, se cuestiona la misma propugnando alternativas que, a veces, tienen un tufillo plebiscitario, o directamente autoritario, que consiguen ocultar a los menos avisados.

No podemos extendernos aquí sobre neoconstitucionalismos, defensas de la democracia participativa, y otras alternativas al modelo sobre el que se fundamentó el pacto constituyente de 1978, pero sí manifestar que creemos que las soluciones a los evidentes problemas no vienen por ahí, sino a través de la perseverancia en la construcción de una democracia de calidad, en la que los partidos sean un verdadero cauce de representación, de un funcionamiento exquisitamente democrático, que hagan llegar a los órganos del Estado las grandes corrientes de ideas, e intereses, presentes en el entramado social.

Hay que ser conscientes que en una democracia de masas todas las alternativas al Estado de partidos son en realidad intentos de lanzarnos a aventuras que no pueden tener otro final que el establecimiento de sistemas autoritarios, por más que se disfracen, de una manera eficaz o no, siempre ha habido clases, de democracias «auténticas» o «verdaderas».

De todo lo dicho anteriormente se deduce que, en mi modesta opinión, el texto constitucional no necesita ser revisado en el sentido de ampliar los supuestos en los que es preciso, o se puede, acudir al referéndum. Una restricción de los mismos quizás pu- 
diera plantearse, sobre todo en el atormentado terreno de la reforma constitucional, pues es hora de reflexionar sobre si hay algún sentido en seguir con esta Constitución no ya rígida sino «pétrea», que nos dimos en 1978.

Pero esto tiene que ver con otro problema, el de las facilidades para el cambio constitucional, tan necesarias ahora y siempre, que abordaré al responder otra de las preguntas que se me plantean. Como se verá más adelante, también en el otro campo en el que da bastante juego el referéndum en nuestro texto constitucional, el de los procesos autonómicos, considero que los tiros debieran ir más por la restricción de este instrumento, que por la solución de ampliar su vigencia.

2. ¿Qué reflexiones le merece el referéndum consultivo establecido en el art. 92 CE? ¿considera adecuado el desarrollo que realizó la LO 2/1980? ¿qué consideraciones nos formularía a la vista de los casos en los que se ha convocado este tipo de referéndum?

\section{JOSE LUIS CASCAJO CASTRO}

A. Se suele comenzar apuntando la extraña ubicación sistemática del $\operatorname{art}^{\circ} 92 \mathrm{CE}$, debido sin duda al contenido que tuvo y luego perdió a lo largo del proceso constituyente. En este sentido es cierto que la elaboración del citado precepto constitucional evidenció un cierto pesimismo democrático. Se ha dicho con razón que el constituyente no fue muy sensible a las demandas de la democracia participativa o de base ni tampoco a la tutela de las minorías parlamentarias. En todo caso el Referendum tiene un significado político original de carácter democrático que no debe pasarse por alto. Así las cosas, nadie duda que la figura del referéndum consultivo puede añadir legitimidad democrática al sistema político.

Es también un lugar común de la doctrina señalar la precariedad de la regulación constitucional de esta institución. Ceñir el objeto de la misma a decisiones políticas de especial trascendencia supone como mínimo apoyarse en un concepto jurídico indeterminado, lo que produce una dosis innecesaria de ambigüedad. Uno de los primeros estudiosos de la materia, Luis Aguiar, reduce el concepto a una decisión básica que postula una política legislativa acorde o unas medidas de gobierno congruentes desde las que ponderar luego el resultado. Acierta este autor al decir que se trata de una institución de carácter excepcional, con contornos ambiguos y sobre la que se proyecta una sombra de desconfianza que la convierte en una figura escasamente operativa para fungir como verdadero instrumento de participación directa de los ciudadanos en los asuntos públicos (tal como reclama el art. 23 de la $\mathrm{CE}$ ), y operar como cauce de modulación de los excesos del régimen parlamentario.

En este sentido hay que añadir que no se especifica bien el ámbito de aplicación de la figura referendaria, de modo que cabría ceñirse a distintos radios de acción, incluido el autonómico, siempre que se guardase la adecuación debida entre el contenido y alcance de la consulta y la población consultada. Tampoco se especifican las mayorías necesarias para producir un resultado vinculante, lo que al fin y al cabo reduce gravemente su alcance institucional. La Constitución no exige un quórum de participación y tampoco contempla el efecto que se produciría en el supuesto de un resultado negativo. Estas y 
otras cuestiones deberían haber encontrado respuesta en la propia Ley de modalidades de referéndum, pero no ha sido así.

En el Referendum consultivo se valora positivamente el cumplimiento del trámite de la autorización por parte del Congreso de los Diputados, en la medida que supone una garantía para la oposición política y el pluralismo.

Tanto el art $^{\circ}$ 92.3 CE como el 62.c) CE tienen un carácter de normas de reenvío, abiertas por tanto a otros tipos de referéndum contemplados en la CE. De modo que este sería el punto de partida para la configuración de un referéndum consultivo de carácter autonómico en el ámbito de las materias de su propia competencia.

B. La L.O.M.R. 2/1980 no recogió, como es bien sabido, los elementos comunes que habrían debido integrar, en buena técnica legislativa, el régimen jurídico general de todas las figuras referendarias contenidas en la CE. Su remisión al régimen electoral general, sin las especificidades que las distintas figuras referendarias requerían, devolvía además a los partidos políticos su protagonismo en este terreno. A juicio de los primeros comentaristas la LOMR diseña defectuosamente el ámbito de la propia ley y en materia de autorización, propuesta y convocatoria adolece de ciertas incongruencias entre lo dispuesto en el $\operatorname{art}^{\circ} 2$ y el art. 7 que repercuten en las distintas modalidades de referéndum.

La citada L.O. 2/1980 es sin duda el resultado de circunstancias políticas muy concretas. Con ella se buscaba mas que la regulación jurídica de una singular institución como el referéndum, la salida a la cuestión del desarrollo autonómico en uno de sus momentos iniciales, a través de las consultas populares entendidas como vías de acceso a la autonomía. Los acontecimientos del momento provocan la reforma de modo poco ortodoxo, para algunos incluso inconstitucional, de su $\operatorname{art}^{\circ} 8.4$ a través de la L.O. 12/1980, entendida como auténtica ley medida para el caso andaluz.

Las críticas a la LOMR son bien conocidas: el resultado es ciertamente discutible, dirá Perez Sola, porque permite caracterizar a la LOMR tanto por sus desaciertos como por sus omisiones, más que por el contenido efectivo de la misma. En términos generales existe una opinión unánime sobre el carácter restrictivo de su regulación. Sus normas de procedimiento son de acusado acento partidario y las de materia electoral terminan por difuminar su propia naturaleza, en lo que hace referencia al referéndum consultivo. En algunos puntos la propia LOMR va más allá de lo que establece la CE al exigir acuerdo de convocatoria adoptado en Consejo de Ministros, contenido en un Real Decreto y aprobado por mayoría absoluta de los miembros del Congreso de los Diputados.

C. En pocas palabras puede decirse que la puesta en práctica del referéndum consultivo no ha respondido a las expectativas y previsiones constitucionales. Dos referéndums (1986 y 2005) no suministran suficiente base empírica como para emitir un juicio sobre tal figura. El alto grado de abstención en el primero de ellos (40.2\%) pudo ser un dato que invita a la reflexión. El protagonismo de los partidos políticos en ambas consultas parece ser también un efecto obligado difícil de evitar.

\section{ELOY GARCÍA}

De lo dicho anteriormente se deduce claramente que el referéndum del artículo 92 de la CE fue una especie de concesión simbólica y políticamente menor de unos consti- 
tuyentes plenamente convencidos de que la democracia y el futuro de la Constitución iban a depender del correcto funcionamiento democrático de los partidos políticos. Sus notas y requisitos característicos — convocado a petición del presidente del gobierno que es al mismo tiempo líder del partido mayoritario, autorizado por el Parlamento y con efectos no vinculantes - hacían de él una figura en apariencia inocua, destinada a reforzar las decisiones políticas de especial importancia de facto ya tomadas por los poderes representativos. Sin embargo, su uso incorrecto terminó provocando hechos inesperados que llevaron a una crisis que en la práctica ha petrificado esta figura jurídica y posiblemente la haya colocado en una tesitura muy parecida a lo que sucediera con el derecho de disolución parlamentario recogido en la Constitución de la III ${ }^{a}$ República francesa, tras la disolución fallida del mariscal Mac Mahon. De ser así estaríamos ante un perfecto ejemplo de mutación constitucional por falta de uso. Y el referéndum de 2005, no es más que la excepción que confirma la regla. Ese referéndum fue un flatus vocis convocado sobre un tema en el que existía unanimidad (de hecho nuestra integración en Europa había sido el gran motor de la transición: los españoles habíamos identificado Constitución y democracia con Unión Europea), y sin repercusión en el debate político interno.

En nuestro caso conviene recordar las circunstancias de aquél referéndum porque tienen mucho que ver con la incorrecta utilización que con frecuencia se viene haciendo de muchos de estos mecanismos. En aquella ocasión la conveniencia del entonces Presidente del Gobierno, Felipe Gonzalez, de hacer compatible el incumplimiento de una de las grandes promesas electorales que le habían llevado al poder — salir de la OTAN_- con el deseo de no aparecer ante la opinión como el líder de un partido que había cambiado de criterio y traicionado su mandato, llevó al jefe del ejecutivo a transferir al cuerpo electoral una decisión que en pura lógica representativa debería corresponder al Parlamento. En este caso el referéndum operó como instancia de contrapeso de la propia responsabilidad política del sujeto que lo convocaba. Se trataba de que la decisión fuera tomada formalmente de manera directa por el pueblo y no por sus representantes mayoritarios que de mantenerse consecuentes con el mandato pedido y recibido, hubieran debido obrar en el sentido contrario. Todo un absurdo constitucional que generó enorme confusión - conviene recordar que la oposición de derecha contrariando su ideología propugno la abstención-y tuvo grandes constes institucionales y políticos (entre ellos los que tienen que ver con la financiación ilícita de la política que aunque no arranca de ahí, recibe en ese momento un gran impulso) de los cuales el mayor se mide en términos de cultura política.

Y es que en esta ocasión, el referéndum del artículo 92, solo sirvió para legitimar la incoherencia y la falta de coraje político de un partido en el gobierno que debería haber asumido democráticamente su cambio de criterio, mediante unas elecciones. Y no se hizo así porque uno de los defectos más graves de nuestro régimen político —imputable en alguna medida a los debes de la transición - fue la debilidad de la cultura política democrática en la vida interna de nuestros partidos que corre pareja a su escasa consistencia en términos de ideas y proyectos, a su falta de previsiones en políticas públicas que son las que generan el autentico debate y no la simple lucha por el poder. El uso indebido del mecanismo del artículo 92, derivó a la postre en un reforzamiento de la irresponsabilidad de los gobernantes y en una banalización del debate político que dejó al margen los temas verdaderamente relevantes. 
Nuestra ya débil cultura política democrática salió considerablemente debilitada del absurdo empleo de un mecanismo cuyo provecho está en contrapesar la excesiva preponderancia de las burocracias que entienden el ejercicio del poder público como si fuera una profesión. Y es que la profesionalización de la vida pública encierra el riesgo de la muerte de la política democrática. En una cultura democrática la política es o debe ser cosa de todos los ciudadanos, independientemente de que sólo unos pocos ejerzan de manera directa cargos públicos, el resto deben participar de manera menos absorbente a través de la vida de partido o de los demás cauces institucionales que se abren en la vida social. Proceder de otra manera significa renunciar a autogobernarse. Por eso las sociedades occidentales europeas de postguerra han alcanzado tan alto grado de democracia efectiva, porque la intensa vida de partidos permitió una participación generalizada de la ciudadanía en la política que se extendía bastante más allá de la acción de los cargos elegidos. Hoy parte de ello ha desaparecido arrastrado por el fin de las grandes ideologías, pero quedan las ideas y la voluntad de los hombres de afrontar problemas que son colectivos y carecen de respuesta individual. Por eso es urgente la tarea de reconstruir la ciudadanía en el cauce de unos partidos que no sean sólo máquinas de poder. Y por eso también, la experiencia del referéndum de 1985 fue negativa, porque consolidó una oligarquía partidista en vez de contrapesarla. Así las cosas, no veo posibilidad ninguna — ni tampoco creo convenienteintroducir cambios sustanciales en la ley que desarrolla este artículo.

\section{JOAN OLIVER ARAUJO}

Como subraya el profesor Aguiar de Luque, la modalidad más novedosa y a su vez problemática de la institución referendaria la consagra la Constitución en su artículo 92.1, al afirmar que «las decisiones políticas de especial trascendencia podrán ser sometidas a referéndum consultivo de todos los ciudadanos». El referéndum consultivo, que tiene un claro precedente en la Constitución de Suecia, es una «figura interesante», tanto por sí misma como, sobre todo, por lo que significa de nuevo intento de incorporar a una Constitución eminentemente representativa algunas fórmulas de democracia directa. En efecto, esta modalidad de consulta popular no interfiere «en el carácter representativo de nuestra democracia ni, sobre todo, en el funcionamiento del régimen parlamentario» (Cruz Villalón).

El artículo $92 \mathrm{CE}$, fruto de un laborioso proceso parlamentario que se prolongó hasta la Comisión Mixta Congreso-Senado, es un precepto ambiguo que, desafortunadamente, apenas ha sido desarrollado por la Ley Orgánica reguladora de las distintas modalidades de referéndum (LOR). En efecto, el artículo 6 de dicha Ley, único que se refiere a esta clase de referéndum, se limita a precisar que la solicitud del Presidente del Gobierno al Congreso de los Diputados «deberá contener los términos exactos en que haya de formularse la consulta», y que la autorización de la Cámara Baja deberá ser por mayoría absoluta. Aspectos tan importantes como el objeto de la consulta, los efectos vinculantes o no vinculantes del resultado, la precisión de lo que debe entenderse por «decisión política de especial trascendencia» o la posibilidad de celebrar referéndums consultivos de ámbito infraestatal, son algunos de los numerosos temas que pasaron 
totalmente desapercibidos para los legisladores, únicamente preocupados por dar una rápida solución al problema autonómico andaluz.

Aunque no es previsible un uso frecuente de esta modalidad de referéndum, debemos recordar que ya ha sido utilizada en dos ocasiones. La primera (1986), rodeado de una gran polémica, para aceptar o rechazar la decisión política del Gobierno socialista de que España se mantuviera en la Alianza Atlántica (el famoso referéndum de la OTAN); la apasionada campaña que precedió a dicha consulta (ya que el PSOE defendía el sí —después de haber preconizado, durante años, el no-; Alianza Popular, la abstención; y el Partido Comunista y las fuerzas a la izquierda del PSOE, el no), unida a lo incierto del resultado hasta el último momento, motivó numerosos artículos y comentarios sobre este mecanismo de consulta directa a los ciudadanos. La segunda vez que se utilizó el referéndum consultivo (2005), también bajo un Gobierno socialista, fue para ratificar el Tratado por el que se aprobaba la Constitución Europea (en este caso, el interés y la participación ciudadana fueron muy escasos, pues tanto el PSOE como el PP defendían — con distinta intensidad - el sí). Ambos referéndums, el de 1986 y el de 2005, tuvieron una respuesta mayoritariamente afirmativa a la propuesta del Gobierno.

Para calibrar el alcance y sentido del referéndum previsto en el artículo 92 de la Constitución, hay subrayar que tiene carácter facultativo, lo que significa que los poderes públicos pertinentes podrían adoptar la decisión política de especial trascendencia sin consultar previamente al pueblo. Dicho con otras palabras, se consulta al cuerpo electoral porque se quiere, no porque haya una obligación jurídica de hacerlo. Sentada esta precisión, debemos señalar que el proceso que conduce a la celebración de un referéndum consultivo se compone básicamente de tres fases: $1^{\mathrm{a}}$ ) propuesta del Presidente del Gobierno (es un acto personalísimo, que acentúa el carácter presidencialista de nuestro sistema político); $2^{\mathrm{a}}$ ) autorización del Congreso de los Diputados por mayoría absoluta (lo que impide que pueda ser utilizado como una alternativa espuria a la confianza parlamentaria); y $3^{\text {a }}$ ) convocatoria formal del Rey. Queremos subrayar que el Congreso de los Diputados autoriza o deniega una solicitud del Presidente del Gobierno, pero carece de competencia para proponer de motu proprio la celebración de un referéndum consultivo. Puede, por tanto, impedir su celebración, pero no puede obligar al Presidente del Gobierno a convocarlo.

La delimitación precisa de lo que puede ser objeto de referéndum consultivo resulta compleja, pues la fórmula «decisiones políticas de especial trascendencia», que utiliza el artículo 92, adolece de una notable y, tal vez, premeditada oscuridad. Ya en los debates parlamentarios, Heribert Barrera puso de relieve la ambigüedad que encerraba dicha expresión, preguntándose: «¿Qué quiere esto decir exactamente?, ¿quién puede juzgar de la trascendencia?, ¿con qué criterio?». A juicio del profesor Linde Paniagua, los constituyentes consagraron conscientemente un concepto jurídico-político indeterminado, «que evidencia el deseo de dejar en el convocante un margen de libertad de extraordinaria amplitud». El profesor Aguiar de Luque ha precisado que por decisión política de especial trascendencia «hay que entender tan solo eso, decisión básica, cuya puesta en práctica puede implicar tanto una política legislativa acorde, como unas medidas de gobierno congruentes con la voluntad popular expresada en las urnas». Se ha pretendido, según este mismo autor, que los poderes públicos puedan posteriormente, al concretar la decisión, «ponderar el resultado de la votación popular». 
Es doctrina generalizada que el referéndum consagrado en el artículo 92 no puede utilizarse para aprobar proyectos de ley ni para derogar leyes en vigor, aunque estos textos contengan decisiones políticas de especial trascendencia. Dos argumentos avalan esta interpretación: por una parte, «el propio tenor literal de este precepto» (Cruz Villalón); y, por otra, el desarrollo del proceso constituyente, pues — como hemos indicado en la primera respuesta - las dos modalidades de referéndum legislativo fueron expresamente excluidas del Anteproyecto de Constitución. No obstante lo anterior, debemos señalar que, aunque la pregunta no puede recaer sobre una norma, es muy posible que el resultado del referéndum provoque una determinada actividad legislativa (por ejemplo, en la hipótesis de que el Gobierno sometiera a referéndum su decisión política de despenalizar el aborto, es evidente que el resultado de esta consulta podría motivar la presentación de un proyecto de ley en consonancia con la voluntad popular). Como afirma el profesor Tomás Villarroya, «el texto literal del artículo 92 puede quedar eludido mediante un expediente fácil: se consulta al pueblo y el resultado de la consulta se articula en un texto legislativo».

La cuestión más importante que plantea el referéndum sobre decisiones políticas del artículo 92 es, a nuestro juicio, la de precisar el alcance y significado del término «consultivo», introducido — como hemos indicado— por la Comisión de Asuntos Constitucionales del Congreso, al ser aceptada una enmienda in voce del profesor Solé Tura. Dicho con otras palabras, lo que ahora nos proponemos es determinar si el resultado del referéndum vincula a los poderes públicos o si, por el contrario, solo tiene carácter orientador, jurídicamente no vinculante. Para abordar este problema resulta útil acudir, en primer lugar, a los debates parlamentarios, al objeto de saber cuál fue la intención de los constituyentes al calificar de «consultivo» al referéndum sobre decisiones políticas. Pues bien, hay que subrayar que su propósito fue, sin ninguna duda, el de recortar la eficacia decisoria de este mecanismo de participación directa, aunque no se llegó a precisar exactamente en qué consistía este recorte. Al leer los debates que tuvieron lugar en el Congreso, da la impresión de que los diputados que defendían esta innovación (concretamente, Solé Tura y Pérez-Llorca) no se atrevían a decir que el resultado de un referéndum consultivo podía no ser vinculante para los poderes públicos, y soslayaban esta afirmación con diversos rodeos dialécticos. Fue el profesor Fraga Iribarne quien, oponiéndose a la enmienda del profesor Solé Tura, puso el dedo en la llaga, subrayando la «extrema gravedad» que supone someter al pueblo una decisión y luego «no tomar en consideración la opinión expresada». Ante estas críticas, los defensores de introducir el término «consultivo» precisaron algo más lo que significaba para ellos este vocablo. El profesor Solé Tura parecía concebir el referéndum consultivo como un gran sondeo de opinión. A su juicio, este tipo de referéndum debería utilizarse cuando, ante situaciones extraordinarias, haya que adoptar decisiones políticas de especial trascendencia que ni el Gobierno ni las Cortes «quieran asumir con plenitud sin saber exactamente cuál es el estado de la opinión, y que se pueda levantar acta de esta opinión». Por su parte, José Pedro PérezLlorca fue todavía mucho más claro. A su entender, el calificar de consultivo al referéndum sobre decisiones políticas traía como consecuencia que, si el nivel de abstención era muy elevado, los poderes públicos no estarían obligados a seguir la opinión mayoritaria, pues esta no reflejaría realmente la voluntad popular. La réplica de Heribert Barrera al diputado de UCD fue inmediata. «¿Cómo puede imaginarse — decía— que se hará una 
consulta al pueblo, que el pueblo contestará en un cierto sentido y que luego no se le hará caso?». Tras agregar que este mecanismo puede dar lugar a «conflictos gravísimos», concluía diciendo que, en un sistema democrático, es inadmisible «pensar que alguien puede oponerse a la voluntad del pueblo, expresada en referéndum». Hasta aquí lo que dieron de sí los debates parlamentarios en torno al significado del término «consultivo» aplicado al referéndum sobre decisiones políticas.

Por otra parte, dentro del ámbito doctrinal, se han defendido tres interpretaciones parcialmente distintas sobre el alcance que hay que atribuir a dicho término. Para algunos autores el resultado de un referéndum consultivo (que sería como una macro encuesta) no vincula jurídicamente a los poderes públicos que, en consecuencia, podrán actuar en sentido contrario al preferido por la mayoría de los ciudadanos. Para otro sector de la doctrina, el referéndum no tendrá carácter vinculante cuando los resultados del mismo muestren «una ciudadanía escindida a nivel de votos», pero, en cambio, la obligatoriedad será total cuando una de las dos respuestas haya «alcanzado una amplia mayoría en el cuerpo electoral» (Ramírez Jiménez). Finalmente, para un tercer grupo de autores —entre los que nos encontramos- el resultado del referéndum es jurídicamente vinculante, con independencia de que la mayoría haya sido amplia o ajustada, y, por tanto, los poderes públicos están totalmente obligados por aquel resultado. Hacer caso omiso del mismo equivaldría — como ha afirmado gráficamente el profesor Jorge de Esteban — a un «verdadero golpe de Estado constitucional, puesto que el sujeto de la soberanía, en última instancia, es el pueblo y él debe ser quien tenga la última palabra en los asuntos de Estado sobre los que se le consulta». Como señala, en esta misma línea, el profesor Torres del Moral, «está fuera de lugar que al pueblo se le asigne una función de consejo. Cuando el pueblo habla, no aconseja, ni sugiere, ni recomienda: decide». Y nosotros añadimos: ¿cómo osarían el Gobierno o el Parlamento ir en contra de la opinión mayoritaria del cuerpo electoral, del que ellos son emanación? Además, para que no quede burlada la voluntad popular, es imprescindible que el resultado del referéndum se ejecute de forma inmediata, sin que el Gobierno pueda disolver el Parlamento antes de dicha ejecución. Lo contrario sería, a nuestro juicio, un inadmisible fraude de ley.

\section{IGNACIO TORRES MURO}

El referéndum consultivo es, con toda claridad, un pequeño absurdo, una especie de complicado ejercicio para satisfacer a los partidarios de la democracia directa, pero reservándome la última palabra sobre «las decisiones políticas de especial trascendencia», si es que el electorado me sale respondón.

No hace falta casi decir que el planteamiento así del problema no tiene sentido. Cuando habla el pueblo soberano los demás poderes deben acatar sin más el resultado, porque esa es la base de toda democracia, como entendió perfectamente el Consejo Constitucional francés en su famosa decisión sobre el referéndum gaullista de 1962

2 Puede verse en FAVOREU y PHILIP Les grandes décisions du conseil constitutionnel, $3^{\mathrm{a}}$ edición, Sirey, Paris 1984, págs. 174 y ss, con el texto de la decisión e interesantes comentarios.

3 PÉREZ SOLA La regulación constitucional del referéndum, Universidad de Jaén, Jaén, 1994, pág. 43. 
(Decisión 62-20 DC, Rec. 27, de 6 de noviembre de $1962^{2}$ ), en el que se cambiaba la forma de elección del Presidente de la República. Recordemos que allí se dice textualmente que las leyes que puede controlar el Consejo son «únicamente las...votadas por el Parlamento y no aquellas que, adoptadas por el pueblo después de un referéndum, constituyen la expresión directa de la soberanía nacional» (Considerando segundo de la decisión).

La pretensión de que existe algo así como un referéndum consultivo simplemente no se sostiene. Una vez que todos los ciudadanos tienen la posibilidad de pronunciarse, la única salida lógica es aceptar su decisión, por mucho que las condiciones, o el resultado de la consulta, no sean especialmente presentables. Considero, por tanto, muy desafortunada este aspecto de la regulación contenida en el artículo $92 \mathrm{CE}$. Sin embargo, la autorización del Congreso de los Diputados parece coherente con nuestro sistema constitucional, en tanto en cuanto supone el reconocimiento de la existencia de supuestos excepcionales en los que pudiera ser necesaria la Appellatio Ad populum simplemente porque los mecanismos habituales de tomar acuerdos se encontraran atascados, o fuera preciso reforzar la legitimidad democrática de determinadas medidas.

En el primer, y en el segundo, sentido es muy ilustrativa la experiencia de Italia, país en el que los mecanismos de democracia directa han servido, en algunos casos, para desbloquear problemas que la clase política (los partidos) no podía resolver por sí sola, o para frenar iniciativas de la misma que era muy dudoso que contaran con un verdadero respaldo popular, como ocurrió con las fracasadas reformas constitucionales de 2006.

Por otra parte, y sobre esto volveremos, la configuración concreta de la campaña y demás reglas que rodean este tipo de referendos hace que se haya podido hablar, correctamente de consultas populares «al servicio de los intereses prohegemónicos del ejecutivo» ${ }^{3}$. Este último rasgo es sobre todo consecuencia del monopolio de la iniciativa del mismo por parte del Presidente del Gobierno (arts. 92.2 CE, y 2 y 6 de la LO 2/1980), monopolio que pone el instrumento al servicio de los intereses de éste, y que desactiva las posibilidades de que se convierta en una manera de desarrollar políticas alternativas, como sucede en los casos, propios de otros países, en los que la apuesta por la democracia directa o semidirecta incluye una regulación en la que sectores significativos de la sociedad (un número razonable de ciudadanos), o instituciones políticas distintas del Gobierno, pueden tomar la iniciativa en un proceso de referéndum destinado, en estos supuestos, a plantear a la ciudadanía soluciones diferentes de las sostenidas por el Ejecutivo. Creemos que si se opta por reconocer algunas formas de participación, diferentes de la democracia representativa, opción con la que somos razonablemente críticos, esto debe hacerse con seriedad, y con todas las consecuencias, y no con una regulación que casi podría calificarse de farsa, si no fuera por lo duro de la expresión.

Esto es especialmente llamativo en otros aspectos de la normativa aprobada en la LO 2/1980, de 18 de enero, sobre la regulación de las distintas modalidades de referéndum. No tengo nada que objetar a la mayoría de las normas que allí se contienen, y que se refieren a aspectos aparentemente técnicos (votación, escrutinio, proclamación de resultados, reclamaciones y recursos), pero soy totalmente contrario a cómo se resuelve el tema de la campaña electoral, con una concesión de espacios (art. 14), que privilegia injusti- 
ficadamente a los grupos con mayor representación parlamentaria, sin tener en cuenta cual es su postura en relación con las cuestiones que se les proponen a los electores.

La regla de oro cuando se plantea al ciudadano una alternativa con dos opciones, o poco más, es que los defensores de las mismas gocen de las mismas posibilidades de hacer llegar sus mensajes al mismo; o al menos que esa sea la tendencia, dado que, en un mundo de pluralismo informativo, este objetivo es muy difícil de alcanzar de una manera perfecta. Pero que el planteamiento de base se configure de manera en que se hace en la LO 2/1980 es abiertamente disfuncional.

El tratamiento de este asunto resulta totalmente desequilibrado y es, pura y simplemente, un sarcasmo, que tiende a favorecer los intereses de los «instalados», y a frenar el desarrollo de posibles alternativas a los mismos. En todo caso, también es plenamente coherente con la desconfianza hacia las formas de democracia directa que ya sabemos que late en todo el texto constitucional. He explicitado más arriba mis recelos hacia la misma, pero, si se hacen las cosas, repito ahora, hay que hacerlas bien, y esta manera de regular la campaña es susceptible de duras, y fundadas, críticas, que pueden ir en el sentido de que la misma vacía de contenido el referéndum, convirtiéndolo en un mero ejercicio de ratificación más o menos plebiscitaria de lo que ha interesado a los que ostentan una posición dominante en el sistema constitucional.

Pasando a la experiencia concretas de referendos consultivos que se han dado en nuestro país, a mi juicio el espectáculo no ha podido ser más deplorable, con unas situaciones en las que el elector se ha encontrado con un verdadero bombardeo a favor de determinadas opciones (casualmente las defendidas por el Gobierno de turno) y con la inexistencia de verdaderos debates sobre los asuntos, entre otras cosas, porque nuestra entrada en la OTAN, o la complejísima problemática que traía consigo el Proyecto de Tratado por el que se aprobaba una Constitución para Europa, no parecían temas que pudieran despacharse con un sumario sí o no.

Por eso, más que verdaderas discusiones que, como sabemos, no pueden tener lugar en un proceso referendario, nos encontramos con numerosos ejemplos de apelación a lo más sagrado, o a la fidelidad a determinadas siglas, que la verdad es que poco tienen que ver con un debate razonado. Quizás esto fuera inevitable, pero la regulación que hemos criticado fomenta esta situación de verdadero ahogamiento del disidente, y uso de las consultas populares para jalear las posturas de los que ya mandan en las instituciones de nuestra sociedad política. De este modo, los ejemplos que hemos conocido de referendos consultivos no aparecen como especialmente brillantes, y sí como dotados de un significativo déficit democrático, por usar la terminología propia de los europeístas.

Cabe recordar, además, que estas reglas que criticamos tienen vigencia para todo tipo de consultas populares, de manera que, lo decimos ahora por si no tenemos la oportunidad de manifestarlo más adelante, tampoco el resto de los referendos que se han celebrado en España pueden considerarse como un ejemplo de buen funcionamiento democrático del sistema. El fantasma de la práctica de los llamados despectivamente plebiscitos se cierne sobre nuestra realidad, como consecuencia de unas normas inapropiadas. 
3. En relación al referéndum en el proceso de reforma constitucional, ¿quiere hacernos alguna reflexión?

\section{JOSE LUIS CASCAJO CASTRO}

No es superfluo recordar que,como se ha dicho, el poder de reforma es poder constituyente y por consiguiente su configuración constitucional ha de asegurar, en la mayor medida posible, que la voluntad del órgano que lleva a cabo la reforma coincide con la del pueblo soberano al que ésta se imputa. Estamos pues más allá del plano de la legalidad ordinaria y parece pertinente asegurar el origen, la voluntad y el procedimiento que se pone en juego a través de un referéndum.

En relación con el referéndum facultativo del $\operatorname{art}^{\circ} 167 \mathrm{CE}$ se equivocaron los que creyeron que se convertiría en trámite obligado para cualquier tipo de reforma, dado el bajo porcentaje fijado en el citado precepto constitucional para solicitar un referéndum. Como se ha puesto en evidencia recientemente con motivo de la reforma del $\operatorname{art}^{\circ}$ $135 \mathrm{CE}$, el acuerdo de los partidos mayoritarios ha orillado las exigencias del pluralismo y la tutela de las minorías. Otros autores insisten sin embargo en el acierto del carácter facultativo de este referendum por obvias razones de economía procesal, si se cuenta con un alto grado de consenso de las fuerzas políticas con representación parlamentaria o son reformas de marcado carácter técnico, suficientemente pactadas.

No hace falta un gran esfuerzo de argumentación para justificar la inclusión de una consulta popular en materia de reforma constitucional. La presencia del titular de la soberanía nacional a través de la manifestación de su voluntad resulta obligada cuando actua como elemento de la renovación del pacto constituyente. Para algunos se trata de una elemental razón de coherencia. Para otros por el principio de «isomorfia» y el de «contrarius actus» respecto al referéndum aprobatorio de la Constitución. Además no se hace depender al principio democrático sólo de la voluntad de los partidos y se refuerza el principio de legitimidad del sistema político.

\section{ELOY GARCÍA}

Entiendo que su propia existencia en el Título X permite corroborar lo anteriormente dicho respecto de la función reservada en el Estado Constitucional a los mecanismos de democracia directa y sobre la dificultad de construir consensos en una sociedad plural y no homogénea. El hecho de incluir un referéndum potestativo en un caso, y forzoso en otro, cono requisito para proceder a efectuar la reforma sólo se explica en base al deseo de proteger a la Constitución contra la reforma. Es un plus de rigidez que únicamente se comprende desde la particularidades que acompañan al proceso de transición política y teniendo en cuenta el deseo de fundamentar sólidamente el valor normativo de la Constitución. A mayor rigidez, se pensó, menor reforma y a menor reforma mayor normatividad de la Constitución. Esta formulación es incorrecta pero probablemente impulsó la inclusión del referéndum en el Titulo X, y nos lleva a la situación actual en que 
sólo un altísimo consenso es posible abordar la reforma de la Constitución, porque el temor al referéndum entre nuestra clase política actúa como barrera disuasoria.

Es así como una institución de democracia directa pasa a desempeñar el rol de mecanismo de control negativo de la acción política de los órganos constitucionales. El referéndum constitucional ha sido introducido dentro del procedimiento de reforma para que esta sólo se lleve a cabo si se consigue reunir previamente un altísimo consenso. Ello significa hacer del referéndum de reforma constitucional un instrumento de control de unas decisiones tomadas a través del principio representativo que requieren de gran unanimidad política. El referéndum constitucional es pues un contrapeso, más que un instrumento de participación democrática que en la medida en que como la decisión ha sido ya adoptada por una muy amplia mayoría política por su previsible resultado genera escaso interés en sí mismo. Lo importante de estos mecanismos de democracia participativa no es tanto la contribución del pueblo decidiendo, como la repercusión que deriva de su potencial acción —y en ocasiones de su simple existencia — sobre los mecanismos de la representación.

Así las cosas, enjuiciar desde la óptica democrática la conveniencia de preservar o no la existencia de esta figura, se convierte en todo un pronunciamiento acerca del grado de consenso conveniente para proceder a la reforma sin necesidad de apelar al pueblo, que en este momento está situado en lo que representa políticamente al $90 \%$ del Parlamento.

\section{JOAN OLIVER ARAUJO}

Desde sus primeras formulaciones doctrinales, «el referéndum ha sido considerado como instrumento adecuado para la ratificación de procesos de reforma constitucional» (Aguiar de Luque). En efecto, fue el marqués de Condorcet (1743-1794) quien, llevando hasta sus últimas consecuencias los planteamientos de Sieyés, teorizó sobre la conveniencia e incluso la necesidad de que las Constituciones contasen con el aval de una consulta popular favorable. En su opúsculo publicado en 1789 bajo el título Sur la nécessité de faire ratifier la Constitution par les citoyens, Condorcet afirma que es preciso que la Constitución sea elaborada por unos representantes extraordinarios, como defiende el abate Sieyés, pero añade que ello no es suficiente, sino que es necesario además que el conjunto de ciudadanos la ratifique. «El pueblo — escribe Condorcet — no ha delegado más que la función de redactar la Constitución, función que él no puede ejercer; pero [en] el rechazo o la aceptación expresa su verdadero deseo». Las influencias del pensamiento democrático de Condorcet son muy claras en el proceso revolucionario francés. Así, el Decreto de 21 de septiembre de 1792, buscando un fundamento legítimo al nuevo orden político, declaraba que «no puede haber Constitución que no haya sido aceptada por el pueblo». Este Decreto, como ha afirmado el profesor Aguiar de Luque, constituye el primer «reconocimiento jurídico» de «la participación popular directa en el poder constituyente». Sin embargo, la plasmación más completa de las ideas de Condorcet la encontramos en el Proyecto de Constitución girondino de 1793, del que fue su principal artífice. En concreto, el artículo 10 del título IX afirmaba que la reforma constitucional solo entraría en vigor cuando hubiera sido aprobada por los ciudadanos. 
Un rápido repaso a las vicisitudes de la institución referendaria durante estos dos últimos siglos demuestra que ha sido, precisamente, en el tema de la aprobación y reforma de las Constituciones donde ha sido aceptada con menos dificultad. Quizá, como afirma el profesor Santamaría Ossorio, porque reconcilia «la noción democrática de la participación directa con la noción conservadora de la rigidez constitucional».

La Constitución Española de 1978, como es sabido, regula dos procedimientos de reforma constitucional: el ordinario (art. 167), para las modificaciones menos importantes, que puede concluir o no con un referéndum; y el extraordinario (art. 168), para las alteraciones esenciales o totales, que necesariamente deberá finalizar con una consulta popular. Como vemos, se han incluido en nuestro sistema político dos tipos de referéndums de reforma constitucional: uno facultativo y otro obligatorio. Aunque ambas modalidades pretenden «acentuar el carácter rígido de la Constitución» (Cruz Villalón) parecen responder a finalidades políticas distintas: «protección de las minorías en el referéndum previsto en el artículo 167, legitimación popular de la reforma en el supuesto contemplado por el artículo 168» (Aguiar de Luque).

\section{IGNACIO TORRES MURO}

Si hay algún caso en el que los referendos aparecen como justificados, este es, sin duda, el de las reformas constitucionales, pero también en este campo pueden formularse algunas críticas, en el sentido de que su presencia en ellas las dota de un grado de dificultad que es posible considerar como exagerado, sobre todo en algunos supuestos.

Dado que no es el tema sobre el que se nos pregunta no creemos que sea necesario más que aludir tangencialmente a una regulación de estos asuntos como la española que, dicho sea con toda franqueza, ha condicionado en exceso las posibilidades de cambio constitucional, transformando el texto de nuestra norma suprema en una especie libro sagrado, al que solamente se le pueden poner pegas, y proponer reformas, cuando los problemas económicos acucian, como en el caso del art. $135 \mathrm{CE}$.

Esa condición de «pétrea», a la que ya hemos aludido, de la Constitución española, reforzada por un sistema político en el que los grandes partidos tienen grandes dificultades, con honrosas excepciones (de nuevo art. $135 \mathrm{CE}$ ), para ponerse de acuerdo en los pactos básicos, y su necesaria reforma, y que ha llevado a una llamativa continuidad de casi todas las decisiones de los constituyentes de 1978, se sostiene, entre otras cosas, por el miedo a tener que convocar alguno de los referendos constitucionales: el del art. 167 CE, que es una posibilidad, como se sabe, y el obligatorio del art. $168 \mathrm{CE}$.

En cuanto al primero, el apartado 3 del art. 167 pone en manos de una minoría tampoco excesivamente significativa de las Cámaras (una décima parte, la misma que en el Congreso puede interponer una moción de censura, art. 113,2 CE) la posibilidad de desencadenar un mecanismo tan complejo, y con tantas incertidumbres, como es un referéndum nacional. Se fomenta así la disidencia en temas constitucionales, pues esta posibilidad parece al alcance de grupos relativamente marginales, y, dado el proceso de fragmentación que está sufriendo el Parlamento español, sobre todo en el Congreso de los Diputados, y en las formaciones de izquierda, tras las elecciones de 2011, ello la hace especialmente preocupante, si de defensa de las decisiones consensuadas entre los partidos 
más representativos contra sectores antisistema estamos hablando. Podría propugnarse, por tanto, o bien la desaparición de este referéndum facultativo, o elevar el quórum necesario para proponerlo, de modo que solamente sectores verdaderamente relevantes de las Cámaras, que en ningún caso deben quedar al margen de los consensos constitucionales, puedan forzar su celebración.

4. En el caso concreto del art. 168 CE ¿le parece correcta la exigencia de referéndum para todos los casos previstos en este artículo? $Y$ ¿qué valoración le merece el procedimiento del art. 168, especialmente teniendo en cuenta que es necesaria la disolución del parlamento, la celebración de elecciones generales, y la constitución de un nuevo parlamento?

\section{JOSE LUIS CASCAJO CASTRO}

Se ha criticado, acaso con razón, la existencia de dos procedimientos de reforma de la Constitución y también la delimitación del ámbito material reservado al procedimiento extremo o superagravado del art $^{\circ} 168 \mathrm{CE}$ que parece no estar satisfactoriamente resuelta. En este sentido resulta difícil de entender la agrupación de materias que ha efectuado el constituyente, como objeto protegido por el procedimiento del citado art ${ }^{\circ} 168$ CE. Por otra parte se apunta que la reforma de muchos de los preceptos cuya revisión ha de encauzarse por el $\operatorname{art}^{\circ} 167 \mathrm{CE}$ puede afectar sustancialmente al contenido de otros sólo reformables a través del $\operatorname{art}^{\circ} 168 \mathrm{CE}$.

Un lugar común entre los comentaristas de este precepto coincide en apuntar su difícil puesta en práctica. Tan difícil que el procedimiento de reforma citado no ha sido utilizado nunca desde la entrada en vigor de la Constitución. La exigencia de un referéndum dentro del ya complejo procedimiento del art ${ }^{\circ} 168 \mathrm{CE}$ supone para algunos un requisito superfluo y se convierte exclusivamente en un obstáculo más para desalentar el proceso de reforma en que hubiera de aplicarse, ya de por sí lento y plagado de requisitos de no fácil cumplimiento. Es cierto, como ha escrito Carlos de Cabo, que el procedimiento agravado del art $^{\circ} 168$ cubre entre otras la función de estabilidad constitucional junto a las de legitimación política y jurídica que se fortalecen en el caso español, dados los caracteres y potencialidades que se recogen en el procedimiento agravado. Pero el resultado del mismo ha sido a la postre la dificultad para introducir reformas razonables cuya necesidad se ha sentido con fuerza a lo largo del tiempo transcurrido desde la entrada en vigor de la Constitución. Este período demuestra que el procedimiento del $\operatorname{art}^{\circ}$ $168 \mathrm{CE}$ no era tanto un mecanismo para la reforma como un expediente normativo para la estabilidad de la propia constitución. De manera que así se entiende que haya funcionado como un espúreo sucedáneo de cláusulas de intangibilidad que no se constitucionalizaron. La rigidez constitucional convierte en regla la estabilidad constitucional y en excepcional su reforma, hasta límites poco recomendables para la salud institucional del sistema político. 


\section{ELOY GARCÍA}

En el entendimiento aquí defendido del referéndum y la idea de democracia directa, la respuesta a esta cuestión tiene más que ver con la categoría de la reforma constitucional y su problemática que con las instituciones de participación democrática. En una encuesta anterior en la que se nos preguntaba por el sistema de reforma, expuse el criterio de que la excesiva rigidez de nuestra Constitución afectaba a todo el sistema político, transcendía al Titulo de la Reforma y era resultado de una determinada idea de Constitución programática que hoy se halla muy en cuestión. Mantengo mi respuesta sólo que insistiendo en que también las instituciones de democracia directa como el referéndum, participan de una dinámica común al entero sistema constitucional.

\section{JOAN OLIVER ARAUJO}

La Constitución Española de 1978 es toda ella rígida, es decir, su reforma requiere el cumplimiento de unos requisitos más exigentes que los que se demandan para aprobar las leyes ordinarias (título X, artículos 166 a 169). Pero, además, tiene unas partes de la misma especialmente protegidas, cuya reforma es en extremo difícil. Así, el artículo 167 CE contiene el denominado por la doctrina procedimiento de reforma ordinario, que se utiliza para las reformas parciales no esenciales de la Constitución (por esta vía se llevó a cabo la alteración del artículo 13.2, en agosto de 1992, y del artículo 135, en septiembre de 2012). Por su parte, el artículo 168 CE regula el procedimiento de reforma agravado, que deberá seguirse cuando se proponga una revisión total de la Constitución o una parcial que afecte a una de estas tres partes de la misma: el título preliminar (artículos 1 a 9), que contiene la mayoría de las decisiones políticas fundamentales de nuestro sistema constitucional; la sección primera del capítulo segundo del título primero (artículos 15 a 29), que consagra los derechos fundamentales y las libertades públicas; y el título II (artículos 56 a 65), dedicado a regular la Corona. Por tanto, desde un punto de vista estrictamente jurídico y al margen de consideraciones políticas, es tan difícil modificar un precepto cualquiera de estas tres partes como aprobar una nueva Constitución. Además, no puede dejar de apuntarse que hay bastantes preceptos protegidos por la vía extraordinaria que tienen escaso relieve constitucional (v.g., el uso de las enseñas de las Comunidades Autónomas — art. 4.2-, la prohibición de los tribunales de honor en ciertos ámbitos — art. 26—, el derecho de petición — art. 29— y el tutor del Rey —art. 60— ) y, por el contrario, hay numerosos preceptos fundamentales de nuestro sistema constitucional que han sido excluidos de dicha tutela extraordinaria (v.g., los fundamentos del orden político y de la paz social —art. 10.1—, los criterios interpretativos de las normas relativas a los derechos y libertades que la Constitución reconoce —art. 10.2—, el principio de igualdad ante la ley — art. 14-, los principios tributarios de igualdad, progresividad y no confiscación — art. 30.1 - y algunos preceptos referidos a las Cortes Generales, al Gobierno, al Poder Judicial y al Tribunal Constitucional. Lo que, ciertamente, no parece demasiado coherente.

El Anteproyecto de Constitución no incorporaba ningún precepto similar al actual artículo 168 (para las reformas totales o parciales esenciales), sino que se establecía un 
único procedimiento reformador (el del actual artículo 167). Su introducción se debió a un voto particular presentado por el Grupo de Alianza Popular. En base al mismo, la Ponencia constitucional, en su Informe (BOC 17-IV-1978), incorporó en el articulado del Proyecto de Constitución este nuevo procedimiento de reforma. En los debates que se sucedieron en la Comisión de Asuntos Constitucionales, la existencia de dos procedimientos de reforma constitucional fue defendida por el diputado Fraga Iribarne, del Grupo Parlamentario de Alianza Popular; en tanto que el diputado Virgilio Zapatero, del Grupo Parlamentario Socialista, se mostró contrario a la incorporación de este procedimiento agravado para las reformas más sustanciales. Sin embargo, con el apoyo de la Unión de Centro Democrático a la propuesta de Alianza Popular, el Pleno del Congreso de los Diputados aprobó el precepto constitucional que consagraba la dualidad de procedimientos de reforma. Acto seguido, el Proyecto pasó al Senado, al objeto de seguir el trámite parlamentario establecido. En dicha Cámara, «el Grupo Socialista y el de Progresistas y Socialistas Independientes presentaron sendas enmiendas, abogando por la supresión» del actual artículo 168, «al entender preferible la existencia de un único procedimiento de reforma». Sin embargo, «ninguna de ellas fue aceptada y el artículo se mantuvo inalterado, pasando así a constituir el definitivo 168» (Santaolalla López).

El procedimiento de reforma agravado exige, en síntesis, los siguientes trámites: mayoría de dos tercios en el Congreso y en el Senado expresiva de la voluntad de reformar la Carta Magna, disolución inmediata de las Cortes (por tanto, con pérdida de sus escaños por todos los parlamentarios), nuevas elecciones generales, ratificación de la voluntad de reforma por las dos nuevas Cámaras (por mayoría simple en el Congreso y mayoría absoluta en el Senado), aprobación del texto de la reforma por dos tercios en el Congreso y en el Senado y, finalmente, referéndum afirmativo entre todo el cuerpo electoral. El incumplimiento de uno solo de estos requisitos o de cualquiera de estas mayorías, al primer intento, frustra totalmente y sin posibilidad de subsanación la propuesta reformadora. Es, por tanto, evidente - como afirma el profesor Jorge de Esteban — que, más que un procedimiento ideado para utilizarse alguna vez, es un conjunto de obstáculos pensados con el objetivo de que nunca lleguen a aplicarse o, dicho con otras palabras, para que sea un procedimiento de reforma «inviable». Para comprobarlo basta que reflexionemos en lo poco coherente que resulta exigir la ratificación de la reforma constitucional por un Parlamento recién elegido, precisamente a causa de que se ha iniciado dicha reforma, y que, inmediatamente después de la aprobación del texto por las nuevas Cortes, también deba convocarse ope legis un referéndum de ratificación. Así, aunque resulta lógico y encomiable que se involucre al cuerpo electoral siempre que se quiera reformar algún aspecto fundamental de la Constitución, creemos que la suma de elecciones obligatorias más referéndum preceptivo no responde tanto a una voluntad democrática, como al deseo de entorpecer todo lo posible una reforma de las partes súper protegidas de la Constitución. En efecto, la campaña electoral, motivada por la reforma constitucional iniciada, tendrá como uno de los puntos centrales de la misma «la conveniencia o la inoportunidad de la revisión». En consecuencia, «si esta resulta nuevamente aprobada por el Parlamento, es porque los electores han dado su visto bueno a la iniciativa de reforma constitucional, otorgando su voto a los partidos que la defienden; de esta manera, la exigencia adicional de un referéndum posterior fijada en el artículo 168 resulta superflua y 
se convierte exclusivamente en un obstáculo más para desalentar el proceso revisionista» (Tomás Villarroya).

A nuestro juicio, los partidos conservadores con mayoría absoluta en las Cortes Constituyentes no se atrevieron a afirmar que la Monarquía, como forma de Jefatura de Estado, era inmodificable, como en cambio sí que lo hacen expresamente - en relación con la forma republicana- las Constituciones de Francia (art. 89, in fine), Italia (art. 139), Portugal (art. 288.1) y Alemania (art. 79.3 en relación con el 20.1). Ello fue así porque, en el fondo, eran conscientes de que - por muy útil que pudiera ser en nuestro contexto histórico - las Monarquías son una anormalidad democrática, que el viento de la historia va eliminado sin vuelta atrás. Sin embargo, a través de la inclusión de la Corona en el ámbito protegido por el artículo $168 \mathrm{CE}$, la Unión de Centro Democrático y Alianza Popular pretendieron introducir una cláusula de intangibilidad encubierta, pues sabían que, sin sus votos, las fuerzas progresistas del Parlamento nunca conseguirían los dos tercios exigidos en cuatro votaciones sucesivas (dos en el Congreso y dos en el Senado). Con la misma intención se otorgó al Senado, una Cámara vacía de poderes importantes en la vida política ordinaria, un papel muy relevante en el procedimiento de reforma constitucional del artículo 168, pues los partidos de centro-derecha pensaban que, aunque podrían perder el control del Congreso de los Diputados —en donde el número de escaños por provincias es, más o menos, proporcional a su población-, siempre mantendrían la mayoría en el Senado, pues la España rural y menos desarrollada (que es la que aporta el mayor número de senadores) siempre les daría su apoyo mayoritario. No es de extrañar, en consecuencia, que algún autor se haya referido al «blindaje constitucional» que protege al Rey y a la institución monárquica en su conjunto. Puede afirmarse, en coherencia con lo anterior, que el origen del artículo 168 está en el deseo de la mayoría conservadora de dar a la Corona una ultra protección, pues pensaba que, al llegar la izquierda al Gobierno de España, lo primero que intentaría sería cambiar la forma de Jefatura de Estado, por lo que era preciso rodearla de unas garantías extremas. Precisamente por ello, no se dieron semejantes garantías a los otros órganos constitucionales, de mayor importancia — sin duda - que la propia Corona, como son las Cortes, el Gobierno, el Poder Judicial y el Tribunal Constitucional. Por tanto, desde un punto de vista jurídico, podemos afirmar que esta súper protección de la Corona está huérfana de apoyatura lógica y coherente.

El procedimiento de reforma agravado se nos presenta, pues, como un baluarte casi infranqueable, construido para defender la Corona frente a eventuales embestidas republicanas. Sin embargo, como ocurre tantas veces en la vida, no todo está «atado y bien atado». En efecto, como se ha encargado de poner de relieve parte de la doctrina, el artículo 168 CE no está protegido por sí mismo (su amparo solo alcanza, como hemos visto, a los artículos 1-9, 15-29 y 56-65). En consecuencia, el artículo 168 podría suprimirse por la vía del artículo 167 (procedimiento de reforma ordinario) y, a continuación, ya podría reformarse la Corona siguiendo los trámites, más razonables, establecidos en este último precepto, que regularía ahora el único iter de reforma constitucional. 


\section{IGNACIO TORRES MURO}

El procedimiento de reforma previsto en el art. $168 \mathrm{CE}$ es simplemente disparatado, y más valía haber incluido en el texto constitucional las correspondientes cláusulas de intangibilidad, tan criticadas, pero que allí donde existen tienen al menos la decencia de limitar sus efectos a decisiones verdaderamente fundamentales.

Quizás lo menos malo del mismo sea la previsión de un referéndum obligatorio (apartado 3), que tiene su lógica si lo que se va a abordar es la reforma de acuerdos constitucionales básicos. En ese sentido tampoco pueden criticarse en exceso las rígidas mayorías parlamentarias, y la disolución de las Cámaras.

La que es simplemente disfuncional, y errónea, es la enumeración de las materias, aparte de la revisión total, que no pueden ser objeto de reforma por la vía del art. 167 CE. Aparentemente, estamos ante partes muy importantes de nuestra Constitución (Título preliminar, derechos fundamentales y libertades públicas, y Corona), pero una segunda ojeada demuestra claramente que no es así, porque se ha optado por proteger todo el contenido de esas secciones, y dentro de ellas se contienen regulaciones de muy segundo nivel, de mero detalle, que debieran poder ser modificadas sin tantos problemas; y otras, como la de la sucesión a la Corona, con la preferencia del varón sobre la mujer en el mismo grado (art. 57.1 CE), que se han quedado obsoletas en relativamente poco tiempo.

No creo que tenga ningún sentido, por poner varios ejemplos chocantes, que el cambio de los colores de la bandera, o el traslado de la capitalidad fuera de Madrid (Título Preliminar), o las normas sobre la Regencia, o la tutoría del Rey menor, o la enumeración de competencias de este (Título II), o las reglas concretas sobre los derechos de reunión o asociación, o la autonomía universitaria (no el principio, evidentemente) de la sección primera del capítulo II del Título I de la Constitución, estén tan fuertemente blindadas como están, y esto ya está provocando problemas y no dejará de provocarlos en el futuro.

¿Qué sucede si queremos que el tutor testamentario del Rey menor pueda no ser español de nacimiento, o sustituir el sistema de comunicación previa en el derecho de manifestación por uno de plena libertad, o incluso de autorización, o que las asociaciones deban en todo caso inscribirse en un registro, no solo a los efectos de publicidad, o añadir alguna competencia más a la enumeración de los supuestos poderes del Rey? Pues que para cambios tan leves, constitucionalmente hablando, como los que hemos apuntado debemos transitar un procedimiento, referéndum incluido, de tal dificultad que echa para atrás al más osado.

Cualquier intento de modificar esos aspectos menores del texto constitucional, pero que han sido absurdamente petrificados, de una manera técnicamente muy torpe, por nuestros constituyentes, se encuentra con un valladar inexpugnable (mayoría de dos tercios, disolución, nueva mayoría de dos tercios, y, finalmente, referéndum), valladar del que quizás la parte más inocua sea la del referéndum obligatorio, que tendría todo el sentido si se estuviera afectando a problemas constitucionales de primer orden, pero que aparece aquí como poco adecuado.

5. Rogamos su opinión sobre el referéndum que se exige para la aprobación y reforma de ciertos Estatutos de Autonomía 


\section{JOSE LUIS CASCAJO CASTRO}

Conviene comenzar diciendo que gran parte de las normas relativas a los tipos de referéndum por los que se pregunta han agotado ya sus efectos y se han convertido así en normas de derecho transitorio, muy relevantes en el proceso de formación del Estado autonómico, tanto porque permitieron conocer la voluntad de las poblaciones interesadas en acceder al autogobierno por la llamada vía del art. $151 \mathrm{CE}$, como para aprobar los estatutos de autonomía elaborados con arreglo al citado art., o también para reformarlos.

Por la experiencia habida pudiera no ser disparatado exigir un cierto porcentaje para los elaborados por el procedimiento del art.151 CE. De forma análoga cabría pensar en la exigencia de un quórum de aprobación de la consulta distinto al de la mayoría de los votos válidamente emitidos en cada provincia, para considerar que ha sido respaldada por los ciudadanos de las Comunidades Autónomas, con la provincia como circunscripción. No se fomentaría así la separación entre la clase política protagonista de los procesos estatutarios de aprobación o reforma y los electores, ni se minoraría tampoco la propia naturaleza de la institución del Referendum en cuanto instrumento de participación política. El contenido del art. 152.2 CE estableciendo el requisito del referéndum es actualmente insoslayable. Como también lo son las normas relativas a la reforma contenidas en los propios Estatutos. Otra cuestión distinta es la de si tuviera que situarse el referéndum no antes sino después de una eventual sentencia del Tribunal Constitucional sobre el Estatuto en cuestión. La desafortunada experiencia que se desprende del último proceso de reforma del Estatuto catalán invita a reflexionar a fondo sobre estas cuestiones.

\section{ELOY GARCÍA}

En su origen la exigencia del referéndum estatutario respondía a razones similares. De una parte en la transición se busco singularizar a determinadas comunidades —País Vasco y Cataluña - cuyo sentimiento nacional era incuestionable y había dado lugar ya en el pasado a formas de organización política autónomas. El referéndum era para ellas una manera de reforzar su identidad particular que además operaba como barrera para los demás territorios que pretendieran constituirse en Comunidades Autónomas y asumir su mismo nivel de competencias. En todo caso se trataba de mecanismos insertos en actos complejos que tenían la condición de trámites que requerían más pronunciamientos de otros órganos representativos. No había aquí rastro alguno de identidad democrática en el sentido Schmittiano del concepto.

Es muy importante dejar claro la verdadera naturaleza de estas instancias de participación directa en el ámbito de la organización territorial del Estado, ya que en este tema frecuentemente se incurre en derivaciones que van o pretenden ir más allá del verdadero significado del referéndum como mecanismo de control democrático del poder. Nada tienen de nuevo estas interpretaciones que confundiendo intencionadamente la participación política constitucionalmente limitada con los esquemas de la democracia de los Antiguos abocan al falseamiento de los efectos de una expresión de la voluntad popular. 
La línea de separación entre la participación democrática que se manifiesta en forma de referéndum y el plebiscito es tan clara técnicamente, como tenue y políticamente frágil en una sociedad desorientada y que empieza a sentir las consecuencias del declive de la acción política de los partidos. En medio del vacío los plebiscitos que se presentan bajo la apariencia inicial de referéndums, corren siempre el riesgo de generar beneficios a los demagogos. No en vano, como señalara Loewenstein, una de las primeras manifestaciones del fraude democrático fueron los plebiscitos convocados por los triunfantes ejércitos revolucionarios franceses para legitimar sus conquistas en territorios vecinos a cuyos pueblos decían liberar. La distancia entre el fraude a la Constitución y el ejercicio constitucional de una potestad es muy sutil y en el momento que estamos viviendo mucho más. Leyendo el trabajo de Iñaki Lasagabaster, un excelente jurista, sobre la ley 9/2008 del Parlamento vasco, llama la atención la ligereza de su definición de democracia. Si democracia es sólo cuestión de decisión y pueblo Schmitt tenía razón y su construcción de democracia de la identidad es actual y válida. Pero no es así, la democracia es organizar el consenso en una sociedad plural, y eso es enormemente complicado y complejo, máxime en un momento en que la destrucción de la cultura política heredada de nuestros mayores lleva a los españoles de hoy a confundir el momento y lo fugaz con lo estable y permanente, la fancy con la realidad, la decisión parcial con la voluntad democrática. Nuestro problema no es de calidad democrática como dice el preámbulo de la ley 4/2010 de Cataluña, si no de salud democrática y utilizo el término salud en su viejo sentido político romano. Para no afrontar los problemas de regenerar la política, aquellos que debían dar ejemplo y asumir responsabilidades derivadas de la administración de la confianza que les ha sido conferida, prefieren eludirla promoviendo nuevas vías de supuesta participación democrática más pura, más directa, más ciudadana. Por ejemplo y en relación con esto último, habitualmente se maneja la palabra ciudadano sin saber de lo que se está diciendo, ignorando lo que enseñan Pocock o Tuck respecto a Hobbes —el gran reedefinidor del Cive moderno- a los que nadie se molesta en leer; el ciudadano es un ser implicado completamente en política al que interesa las decisiones y las políticas, no las circunstancias personales y privadas de los gobernantes maximizadas por los medios virtuales... estamos iniciando una vía muy peligrosa, más como sociedad que como Estado: la de la destrucción de la cultura política democrática y su sustitución por un vacio.

\section{JOAN OLIVER ARAUJO}

El acceso a la autonomía por la vía del artículo 143 o por la del artículo 151 CE no solo comportaba diferencias en las competencias que se podían asumir ab initio, sino que también repercutía en la forma de elaborarse y aprobarse el correspondiente Estatuto. Los territorios que podían alcanzar de forma directa el grado máximo de autogobierno, bien por haber plebiscitado afirmativamente proyectos de Estatuto de Autonomía durante la Segunda República (caso de Cataluña, País Vasco y Galicia) o bien por haber superado los obstáculos establecidos en el primer párrafo del artículo 151 CE (caso de Andalucía), debían someter sus proyectos de Estatuto de Autonomía a «referéndum del cuerpo electoral de las provincias comprendidas en el ámbito territorial del proyectado Estatuto» (art. 151.2, $3 .^{\circ}$ y $5^{\circ}$ ). 
El procedimiento para elaborar el Estatuto de Autonomía de los territorios que seguían la vía rápida está básicamente regulado en los cinco párrafos del artículo 151.2 de la Constitución y en el artículo 9 de la Ley Orgánica de Referéndum (LOR). Sin entrar en el análisis de estos complejos trámites, cuestión ajena a la pregunta formulada, ahora solo queremos subrayar que - tanto si había acuerdo entre la Comisión Constitucional del Congreso y la delegación de la Asamblea de parlamentarios regionales como si no lo había y, en consecuencia, el proyecto de Estatuto debía tramitarse como un proyecto de ley- el texto propuesto debía gozar del respaldo popular manifestado a través de un referéndum afirmativo. En torno a este referéndum, que ya se exigía en el artículo 12 de la Constitución republicana de 1931, queremos destacar que el quórum necesario de respuestas afirmativas era sensiblemente inferior al que se requería en el referéndum para ratificar la iniciativa autonómica, esto es, aquel que debía celebrarse para que una proyectada Comunidad Autónoma pudiera acceder a la autonomía plena por la vía rápida sin reunir los requisitos que exige la disposición transitoria segunda de la Constitución (art. 151.1). En efecto, como es sabido, en este último supuesto era preciso que en cada provincia hubieran votado afirmativamente «la mayoría absoluta de los electores», en cambio para aprobar los Estatutos de Autonomía era suficiente «la mayoría de los votos válidamente emitidos en cada provincia» (art. 151.2 $4 .^{\circ}$ y 5. ${ }^{\circ}$ y art. 9.2 LOR). Es evidente, pues, que en el referéndum por el que ahora se nos está preguntando no se exigía quórum mínimo de participación, y era suficiente con que la mitad más uno de los votos válidos hubiera sido favorable al texto estatutario propuesto, hecho este cómputo provincia por provincia (Linde Paniagua y Herrero Lera). Este tipo de referéndum autonómico se ha utilizado en cuatro Comunidades (Cataluña, Euskadi, Galicia y Andalucía) y en todas ellas, con diferentes porcentajes de participación y apoyo, los resultados han sido positivos.

Los Estatutos de Autonomía de estas cuatro Comunidades Autónomas —es decir, los que fueron aprobados en una consulta popular - solo «podrán ser modificados mediante los procedimientos en ellos establecidos y con referéndum entre los electores inscritos en los censos correspondientes» (art. 152.2 CE). El artículo $10 \mathrm{LOR}$ precisa que este referéndum requerirá el cumplimiento previo de los trámites de reforma establecidos en el Estatuto de Autonomía que se quiera modificar o, «en su defecto, de los que fueran precisos para su aprobación, debiendo ser convocado [el referéndum] en el plazo de seis meses desde el cumplimiento de los mismos».

El requisito constitucional de que cualquier reforma de los Estatutos elaborados por la vía del artículo 151.2 CE deba ser ratificada por el pueblo, a través de un referéndum, ha sido recogido y desarrollado por los cuatro Estatutos de Autonomía de las Comunidades especiales: País Vasco (arts. 46 y 47), Cataluña (arts. 56 y 57 del primer Estatuto y arts. 222 y 223 del Estatuto actual), Galicia (arts. 56 y 57) y Andalucía (arts. 74 y 75 del primer Estatuto y arts. 248 y 249 del Estatuto actual). Con este requisito, justificado por el hecho de que su aprobación también requirió la participación directa de los ciudadanos (Jorge de Esteban), se ha querido acentuar el carácter rígido de la «norma institucional básica» de la Comunidad Autónoma (en el mismo sentido se ha expresado Cruz Villalón). Por otra parte, aunque ni la Constitución ni la Ley Orgánica del Referéndum han previsto el quórum preciso para ratificar la reforma de los Estatutos, parece lógico entender que se exigirá el mismo porcentaje que se demandó para aprobarlos (esto 
es, la mayoría de los votos válidamente emitidos), asimismo también parece evidente que el cómputo deberá efectuarse provincia por provincia.

Para concluir la respuesta a esta pregunta, queremos plantear la cuestión de determinar si los Estatutos de las Comunidades Autónomas de segundo grado hubieran podido exigir, amparándose en la cláusula abierta del artículo 147.3 CE, que la reforma de los mismos fuera aprobada en referéndum entre los electores inscritos en los censos correspondientes. En torno a esta posibilidad hay que subrayar que la doctrina se ha mostrado dividida. Mientras que algunos autores se inclinan por aceptar esta posibilidad invocando «la libertad que al respecto establece el artículo 147.3» (Entrena Cuesta), otro sector doctrinal estima que sería "poco consecuente» interpretar los preceptos constitucionales en el sentido de admitir que fuese más agravado el procedimiento de reforma de un precepto cualquiera del Estatuto, por insignificante que fuera, que el de aprobación del Estatuto entero, que — como sabemos- en las Comunidades de vía lenta no exige referéndum (Muñoz Machado). De hecho, ninguno de los trece Estatutos de las Comunidades de régimen ordinario ha previsto, ni en su redacción originaria ni en sus reformas posteriores, el requisito de la ratificación de su reforma a través de una consulta popular.

\section{IGNACIO TORRES MURO}

Siempre me ha resultado curiosa, y ya sabemos que no ha dejado de plantear problemas serios, esa apelación al cuerpo electoral de una Comunidad Autónoma cuando se trata de aprobar, o reformar, su Estatuto de Autonomía. Como he mantenido repetidamente una posición que concibe a este como un instrument of government, completado con la enumeración de las competencias autonómicas, los intentos de crear «semiconstituciones» con declaraciones de derechos, y regulaciones muy detalladas de ciertos temas, me parecen inadecuados.

En esa tendencia se inscribe la de implicar al electorado en la aprobación de una norma que creo que el constituyente concibió como un mero instrumento para articular las relaciones Estado-Comunidad Autónoma, y que ahora se pretende que sea mucho más. Son especialmente significativas las reglas de algunos de los Estatutos más recientes (Aragón, art. 115.7; Valencia, art. 81.5; Andalucía, art. 248.3; Cataluña, arts. 222.1.b, y 223.1.b), en ciertos supuestos, como en los dos primeros, no exigidas por la norma constitucional. La previsión, como ineludible, de la figura del referéndum, no tiene en ellos ninguna justificación.

No hay que olvidar, por otra parte, que la exigencia de consulta popular está prevista en las normas que se recogen en los arts. 151 (apartado 2, puntos $3^{\circ}$ y $5^{\circ}$ ) y 152.2 CE. Estas soluciones me parecen desafortunadas, pues dotan a las previsiones de algunos Estatutos de Autonomía de una rigidez absolutamente innecesaria, dado los grados de detalle que se han alcanzado en esas normas, grados de detalle propios de un reglamentismo que se compadece mal con las pretensiones semiconstitucionales que las inspiraban, si es que manejamos el concepto de Constitución propio de las democracias occidentales.

Es de recordar como algunos se han llenado la boca, a la hora de defender opciones dudosamente constitucionales tomadas por los Estatutos, con el argumento de que se había pronunciado el pueblo de la correspondiente nacionalidad o región (por cierto, con 
unos porcentajes de participación más bien escasos, en todos los supuestos) y que, por ello, no era posible implementar los correspondientes controles de constitucionalidad, en un razonamiento que recuerda el del Consejo Constitucional francés, que vimos más arriba, y que olvida que el cuerpo electoral de una Comunidad Autónoma no es, en ningún caso, un ente soberano, puesto que esta condición se predica en nuestra norma suprema exclusivamente del pueblo de toda la nación española (art. 1.2 CE).

Nos encontramos, pues, ante un órgano más de los que desarrollan sus actividades sometidos a nuestra ley fundamental, y, por ello, sometidos a la jurisdicción constitucional que puede, sin ninguna duda, controlar la constitucionalidad de los Estatutos de Autonomía, como por otra parte establecen taxativamente los arts. 161 a) CE («leyes y disposiciones normativas con fuerza de ley», como los Estatutos) y 27.2. a) LOTC («Los Estatutos de Autonomía y las demás Leyes orgánicas»).

No parece descaminado, por tanto, propugnar la revisión de este estado de cosas, suprimiendo la intervención de dicho electorado en los procedimientos de aprobación, y reforma, de las normas superiores de las Comunidades Autónomas. Se nos dirá que eso podría dar lugar a una suerte de déficit democrático, pero creemos que la participación en esos procedimientos de los parlamentos, autonómicos y estatal, es suficiente para garantizar que este problema no se plantee.

Al menos, y esto lo ha dicho más de uno con toda la razón, aunque sea a toro pasado, debió establecerse la regla de que el electorado se pronunciara después de que el Tribunal Constitucional hubiese decidido sobre la constitucionalidad del Estatuto, lo que hubiera evitado presiones innecesarias sobre el órgano revisor. En todo caso, hay que recordar que el Estatuto es ley del Estado, tanto como cabeza del ordenamiento de la Comunidad Autónoma, y, por tanto, el cuerpo electoral de ésta no tiene el monopolio de la última decisión sobre el mismo, como si de su Constitución (el eterno problema del mito Estatuto-Constitución, que subrayara en su momento Muñoz Machado) se tratara, y es perfectamente razonable que instituciones nacionales como las Cortes Generales, y el Tribunal Constitucional, se pronuncien sobre su adecuación al ordenamiento constitucional español, en el que se integra.

6. Por último, ¿qué características técnicas considera que debería tener una consulta a los ciudadanos para entender que el resultado de la misma es expresión clara de la voluntad de los mismos y en qué supuestos? ¿sería necesario para ello exigir un quórum determinado de participación? ¿sería suficiente una mayoría simple o debería exigirse una mayoría cualificada?

\section{JOSE LUIS CASCAJO CASTRO}

Ya se ha apuntado alguna idea a esta cuestión en la respuesta a la pregunta anterior. De todos modos, el silencio de la constitución seguido del de la LOMR en los supuestos del referéndum consultivo, constitucional y autonómico (salvo el del art ${ }^{\circ}$ 151.1CE), induce a pensar que no se ha querido exigir quórum alguno de participación. Pero podría habérsele exigido, aunque con ello se tensionara la relación con el principio re- 
presentativo-partidista. Tampoco tiene sentido en el referéndum consultivo la exigencia de un quórum para la validez del mismo. Con el referéndum se obtiene un pronunciamiento positivo o negativo en base a los votos emitidos, pero en ningún caso permite que el rechazo tenga lugar en base a la abstención. En todo caso lo que revelaría es un alto grado de desconfianza en la participación popular, reflejo de un debilitamiento de los poderes establecidos que se distancian así del electorado.

En mi opinión el porcentaje de votos necesario para que se entienda afirmativamente el resultado de un referéndum debería ser el de la mitad más uno de los votos emitidos, es decir, cuando de entre los votantes son los más y no los menos, los que den su voto favorable. Por regla general, en ausencia de una distinta solución constitucional, se suele exigir que la ratificación popular por medio de referéndum sea por mayoría de votos válidamente emitidos. Se entiende por votos válidos los positivos o negativos con exclusión de los votos nulos y los votos en blanco, ya que estos últimos equivalen a la abstención.

En este punto conviene recordar con los clásicos que la mayoría podrá determinar su función formuladora de la voluntad colectiva sólo dentro de determinados límites materiales y formales. De modo que tendrá que respetar una serie de condiciones que se configuran como derechos fundamentales en todo Estado de Derecho bien constituido. En pocas palabras conviene no olvidarse que también la mayoría está sujeta a la acción del Derecho.

Sobre el principio de mayoría cualificada el pensamiento kelseniano apunta que, bajo ciertas condiciones, puede suponer una aproximación aún mayor a la idea de libertad, en la medida en que puede implicar una cierta tendencia a la unanimidad en el proceso de formación de la voluntad de la comunidad.

\section{ELOY GARCÍA}

El principal problema respecto de cualquier clase de referéndum parece estar centrado siempre en los quórums y en su cómputo. Se trata de una cuestión prolija no exenta de importancia material desde un entendimiento schmittiano o plebiscitario de la institución refrendataria. Pero cuando se considera, como es mi caso, que el referéndum, y con el todas las instituciones de participación directa son supuestos normales y nada especiales del funcionamiento del Estado Constitucional, el problema pierde fuelle y pasa a ser equiparable a cualquier otro relacionado con la dinámica electoral general de la democracia de partidos. Así también, la forma de plantear el referéndum se convierte en un tema puramente técnico y pierde su mística sustancial.

Lo importante es, por tanto, clarificar el significado en democracia del referéndum como instrumento de acción de gobierno ordinario. Una vez clarificado esto corresponde a la ley precisar los quórums en función del diferente tipo de referéndum. Y desde la perspectiva de la situación actual a lo que hay que atender es a la significación democrática del referéndum. Y cuando hablo de democracia dejo claro lo que implica: pluralidad social, consenso en la decisión, voluntad de integración y problemas reales de la sociedad a afrontar, no huir de su responsabilidad por quienes detentan un mandato representativo. En este punto recuerdo la soflama de Louis Veuillot: «reclamo de vosotros y en nombre de vuestros principios, los derechos que os niego en nombre de los que me son propios.» 


\section{JOAN OLIVER ARAUJO}

El referéndum es una institución extremadamente polémica en la doctrina, lo cual no debe extrañar si se tiene en cuenta que ha sido utilizada con finalidades antagónicas y por «los regímenes políticos más dispares» (Linde Paniagua). En efecto, aunque en una primera impresión se podría pensar que el referéndum es el método de decisión democrático por excelencia, pues el pueblo decide sin ningún tipo de intermediarios, hay que ser muy precavidos antes de pronunciarse sobre su santidad democrática. «La historia — como afirma Jorge de Esteban — nos enseña que han sido precisamente los enemigos de la democracia los que han utilizado con más frecuencia esta forma de consulta popular». Karl Friedrich, en la misma línea, ha subrayado que «los plebiscitos constituyen uno de los métodos predilectos de los dictadores, buscando en su autoridad un fundamento legítimo» a su poder despótico. Y Karl Loewenstein afirma que, la razón de esta llamativa popularidad del referéndum entre los enemigos de la libertad, hay que buscarla en «el hecho de que la votación de [un] referéndum se puede manipular con propaganda y presión mejor que el procedimiento» de elección de una «asamblea representativa, ciertamente más racional». De hecho, numerosas experiencias históricas, tanto foráneas como propias, parecen abonar esta tesis. En efecto, desde Napoleón a Pinochet, muchos dictadores lo han utilizado «para buscar — y forzar — un voto de adhesión incondicional» a su persona y a su sistema político (J.M. Laboa y F.J. Vanaclocha). Las predilecciones, por ejemplo, de Hitler o Nasser por el referéndum no han hecho sino aumentar los recelos con que es contemplada esta institución. En España, asimismo, tenemos dos experiencias de referéndums celebrados en un contexto autoritario (plebiscitos de 1947 y 1966). La carencia absoluta de libertades, unida a una cuidada campaña oficial y a la imposibilidad de defender con eficacia respuestas distintas a la del partido único, convirtieron dichas consultas en un burdo mecanismo para intentar legitimar ante la comunidad internacional un régimen político en el que el pueblo carecía de cualquier protagonismo.

A nuestro juicio, sin negar que algunos de los reparos que se han dirigido contra el instituto del referéndum son realmente preocupantes, parece fuera de toda duda el carácter genuinamente democrático del mismo (Aguiar de Luque). Es cierto que su utilización ha servido con frecuencia a regímenes políticos autocráticos y despóticos, pero también lo es que ni por su naturaleza ni por sus orígenes históricos se puede calificar al referéndum de antidemocrático, sino más bien todo lo contrario. Sin desconocer, por tanto, «la ambivalencia que en la práctica política ha comportado acudir a fórmulas referendarias, y siendo también conscientes de la dificultad que encierra el ejercicio de la democracia directa o semidirecta en los Estados contemporáneos, el referéndum nos sigue pareciendo no solo una fórmula inserta en la legitimidad democrática», sino también «un instrumento útil en la toma de decisiones colectivas» que requieran de un especial consenso (Linde Paniagua y Herrero Lera).

Siguiendo al profesor Jorge de Esteban, podemos señalar las tres condiciones necesarias para lograr que el referéndum tenga «una validez realmente democrática». En primer lugar, es imprescindible que la consulta se lleve a cabo en un Estado de Derecho, con todas las garantías formales y materiales que esta fórmula política implica. Ello comporta, como es obvio, «que el referéndum no es, ni puede ser, más que otra de las varias instituciones utilizables en una democracia en donde exista ya un pluralismo político y 
unos derechos fundamentales garantizados. Pero, en ningún caso, puede ser la única vía de participación popular» en la vida política. En segundo lugar, es necesario que el referéndum recaiga sobre una materia adecuada y que la pregunta esté correctamente formulada. «Un referéndum mal planteado o excesivamente técnico no supondrá la aclaración del tema» controvertido, ni dará «legitimidad a la consulta». No es posible desconocer que la respuesta dependerá en gran medida de los términos, más o menos tendenciosos, en que la pregunta se haya formulado a los ciudadanos. Finalmente, en tercer lugar, para la validez democrática de las consultas referendarias, se exige un adecuado control de los medios de comunicación de masas de titularidad pública y, muy especialmente, de la televisión. En aras de la libertad de expresión, es imprescindible garantizar que las diversas organizaciones políticas, sociales, económicas, religiosas y culturales podrán acceder de forma equitativa a estos medios de comunicación públicos y, al mismo tiempo, habrá que adoptar todas las medidas de control necesarias para que el Gobierno no use de ellos de forma abusiva. A nuestro juicio, si se cumplen estas tres condiciones, el resultado de un referéndum debe ser siempre vinculante, con independencia del quórum de participación (los ciudadanos que se han abstenido han renunciado a ejercer su derecho de participación política) y de la mayoría lograda (pues, en caso contrario, se impone la voluntad de la minoría sobre la voluntad de la mayoría).

\section{IGNACIO TORRES MURO}

La primera característica técnica, que es totalmente necesaria para que se pueda hablar de un referéndum «limpio», y que ha sido completamente descuidada por nuestra legislación, es la absoluta igualdad de oportunidades entre quienes propugnen una opción, y los que hagan lo propio con la otra.

Algo dijimos más arriba pero creemos necesario reiterar aquí que es escandaloso el espectáculo vivido en los referendos celebrados en nuestro país desde la vuelta de la democracia, en los que el aparato de propaganda de los medios públicos, o privados, se volcaba en defensa de unas determinadas soluciones.

Solamente cuando se establezcan, con toda claridad, reglas muy estrictas en el sentido de igualdad en financiación, espacios en medios de comunicación, etc, podrá hablarse de que efectivamente estamos ante una situación de verdadera limpieza en el proceso referendario, situación que, todo hay que decirlo, no se ha dado hasta ahora nunca en España.

Ha sido habitual que las opciones más agradables al poder hayan sido apoyadas con el correspondiente aparato mediático, y con todo tipo de facilidades económicas, mientras que las otras se hayan encontrado con serias dificultades para hacer llegar su mensaje a los ciudadanos. Aquí parece imprescindible aprobar una normativa que fomente esa tendencia a la igualdad entre todas las posturas, dado que la igualdad absoluta aparece como muy difícil de conseguir, y mientras esto no sea así no podremos hablar de verdaderos referendos, en los que se exprese fehacientemente la opinión del cuerpo electoral.

Respecto al problema del quórum de participación no parece una idea en absoluto disparatada. No recuerdo cuando se introdujo por primera vez, pero sí el papel decisivo que representó en los referendos británicos de los años setenta del siglo pasado, que tuvieron como consecuencia la paralización, en aquel momento, del proceso de devolución 
de poderes a Escocia y Gales, proceso que, como se sabe, se retomaría en los años noventa, esta vez con éxito.

También es preciso recordar las exigencias del art. 151 CE («mayoría absoluta de los electores de cada provincia» para la iniciativa autonómica, en el apartado 1, y «mayoría de los votos válidos emitidos en cada provincia», para la aprobación de los Estatutos, en el apartado 2, puntos $4^{\circ}$ y $5^{\circ}$ ) y de su desarrollo en la Ley Orgánica de Modalidades de Referéndum (arts. 8 y 9), que tantos problemas plantearon en su aplicación al caso de la iniciativa autonómica andaluza.

La primera respuesta posible es la clásica de que quien se abstiene en una elección vota con la mayoría, respuesta que, reducida al absurdo, serviría para propugnar que incluso cuando hubiera un único voto favorable a una opción, de un electorado razonablemente amplio, si la contraria no tuviera ningún voto, y el resto fuera una abstención masiva, triunfaría aquélla.

Creemos que esta misma reducción al absurdo demuestra lo inviable de dicha manera de ver las cosas, pero, concedido que hacen falta, primero, unos ciertos niveles de participación para que el referéndum pueda ser considerado válido, y, segundo, el pronunciamiento de una mayoría reforzada de los participantes para que la medida sea aprobada, nos encontramos con el problema de fijar esos límites, asunto este que puede abordarse de manera distinta dependiendo del tipo de consulta de que se trate.

En mi opinión, pudiera convenirse en que la exigencia de que participe la mitad del cuerpo electoral es razonable, y que también lo es la de que al menos la mitad de los votantes se pronuncien a favor de la medida que finalmente se apruebe. Se nos dirá que esto pone en manos del 25 por 100 de los electores la decisión, y que esos porcentajes son muy bajos, pero creemos que son lo suficientemente significativos para garantizar que de una manera aproximada se conozca la voluntad del cuerpo electoral en los casos menos conflictivos.

No hay que descartar, sin embargo, que, para tomas de postura de especial trascendencia, se exija un quórum reforzado, que pudiera llegar a la previsión de que sea necesaria la aprobación de la medida por la mitad más uno de los electores, en un intento de favorecer las posiciones de los grupos minoritarios, y conseguir que el acuerdo que se tome sea expresión de una parte significativa del electorado, como está claro que debe suceder cuando las decisiones tengan una gran relevancia para el futuro de la correspondiente comunidad política.

No es necesario aclarar que digo esto pensando especialmente en posibles referendos de independencia de determinadas entidades subestatales, desde el momento en que en ellos se tomaría un acuerdo que conmovería los cimientos mismos de la convivencia, y las relaciones, entre esos entes y el Estado, por más que convenga empezar a desdramatizar lo que podrían considerarse como «falsas independencias», concebidas para satisfacer los intereses de las elites locales, pero que, dada la sujeción de todos a las reglas propias de la Unión Europea, en lo que respecta a las libertades básicas de la misma (art. 26.2 del Tratado de Funcionamiento de la Unión Europea: «El mercado interior implicará un espacio sin fronteras interiores, en el que la libre circulación de mercancías, personas, servicios y capitales estará garantizada....»), no tendrían, ni mucho menos, la importancia que algunos fantasiosos les atribuyen. 
7. ¿Considera inconstitucional la ley aprobada por el Parlamento de Cataluña Ley 4/2010, de 17 de marzo, de consultas populares por vía de referéndum? En caso afirmativo, ¿por qué motivo?

\section{JOSE LUIS CASCAJO CASTRO}

Recurrida ante el Tribunal Constitucional la Ley 4/2010 de consultas populares por vía de referéndum , aprobada por el Parlamento de Cataluña, sería aventurado cuando no improcedente por mi parte, hacer un juicio previo de inconstitucionalidad.

Pero a la vista de los datos normativos y jurisprudenciales de los que dispongo cabe explicar el estado de la cuestión de este reciente contencioso.

Si el Tribunal Constitucional sostiene los fundamentos jurídicos en esta materia que argumentó en sus SSTC 103/2008 y 31/2010 la citada ley impugnada no superará probablemente el examen de constitucionalidad, por carecer la misma de la suficiente cobertura competencial.

El Consell de Garanties Estatutaries ya intervino sobre este asunto con su Dictamen 3/2010 de 1 de marzo. En él se subraya la dimensión institucional del referéndum en base a la potestad de autoorganización de las Comunidades Autónomas. Se subraya también la similitud con el referéndum de ámbito estatal buscando que las instituciones de los dos niveles presenten unos rasgos que permitan su actuación congruente, buscándose así la cobertura constitucional necesaria. El Consell sostiene que la ley catalana no tendría competencia para manifestar qué órgano del Estado es el encargado de aprobar la autorización del referéndum y lo mismo ocurre por analogía en el punto que regula la convocatoria. Concluye que estos aspectos son contrarios al art. 122 del Estatuto de Autonomía de Cataluña y al art. 149.1.32 de la CE. En cambio el proyecto de ley examinado no invade, a su juicio, la reserva de ley orgánica establecida en el art. 92.3 CE ni la L.O. 2/1980. Tampoco rebasa los límites derivados de la reserva de ley orgánica establecida en el art. 81.1 CE en relación con el art. 23.1 CE.

Posteriormente el Dictámen 15/2010 de 6 de julio del citado órgano concluye en relación con la propuesta de consulta popular por via de referéndum sobre la independencia de la nación catalana, que es contraria a los artículos 29.6 y 122 del Estatuto de autonomía de Cataluña.

Finalmente debe tenerse en cuenta el reciente Auto del Tribunal Constitucional 87/2011, de 9 de junio de 2011, por el que se levanta la suspensión de los arts. 1 a 30, 43 y 45 de la Ley de Cataluña 4/2010, de 17 de marzo, dado que en sus fundamentos jurídicos se contienen argumentos pertinentes con la materia objeto de esta encuesta.

\section{ELOY GARCÍA}

El hecho de que por mucho que nos empeñemos en establecer distingos, la temática del ejercicio de un referéndum hace posible que se conciten y reúnan en un aparente mismo plano práctico de acción, razones democráticas, argumentos de la democracia de la identidad, y elementos demagógicos y cesaristas debiera obligar a los constitucionalistas 
a ser más escrupulosos y a tomar grandes precauciones cuando se opera con un instrumento como este. Desde la lógica jurídico-constitucional, en principio y en rasgos generales, la Ley de consultas del Parlamento de Cataluña tal vez me pudiera parecer admisible. Pero, sin embargo, desde la lógica del momento político actual, no estoy muy seguro que respete el límite constitucional que define estas figuras como un procedimiento de contrapeso de la democracia representativa en su faceta partidista. Creo que el sentido de la ley se orienta más a buscar un instrumento de conflicto territorial entre la Comunidad Autónoma y el Estado, que a procurar un ejercicio democrático del poder de control.

En un momento como el actual, incorporar o establecer legalmente nuevos mecanismos de democracia participativa desde una ambigüedad calculada que mezcla elementos de la democracia de la identidad y de la demagogia, cuando se sabe que no es legítimo, me parece una decisión plenamente objetable desde el punto de vista de la lealtad constitucional.

La Constitución es mucho más que un puñado de normas, responde a una determinada lógica de valores que no resultan compatibles con ciertas lecturas basadas en el único afán de procurar obtener una mayoría coyuntural favorable, como decía por escrito Anschütz, en 1933, al Ministro de Educación en la carta en que le pedía el pase a la situación de jubilación anticipada ante la imposibilidad de continuar explicando Derecho público en un régimen que a pesar de las formas ya no era compatible con la Constitución y reproduzco sus dignas palabras de 1933: «La tarea de enseñar el derecho público alemán ... rebasa la ciencia jurídica para ser también política. El cometido del profesor de esta disciplina no sólo consiste en transmitir a los estudiantes el conocimiento del derecho público alemán, sino el de instruirles en el sentido y el espíritu del vigente orden constitucional. Siendo, en este punto donde resulta imprescindible un íntimo convencimiento del compromiso del docente con ese orden. La fraqueza, que es para mí un deber, me exige reconocer la imposibilidad de mantener, en este momento, tal compromiso con el nuevo derecho público alemán que ahora se está formando.

\section{JOAN OLIVER ARAUJO}

Al ser probable que una norma muy similar a la Ley catalana 4/2010, de 17 de marzo, de consultas populares por vía de referéndum, llegue al Consejo Consultivo de las Islas Baleares para ser dictaminada, me abstendré de responder a esta pregunta, pues si lo hiciera quedaría — sin duda - contaminado para poder intervenir en el debate que, en su momento, se suscitará en dicho órgano autonómico de consulta y en la posterior votación.

$$
* * *
$$

TITLE: Academic Survey: Referendum

ABSTRACT: In this academic survey Constitutional Law Professors answer some questions about the referendum in the Spanish Constitution. Referendum is an instrument of direct democracy, of direct participation, but bistorically its use was problematic; therefore, our Constitution establishes its utilization in very limited cases. In any case, it is an adequate way to promote citizens participation. 
RESUMEN: En esta encuesta diferentes profesores de Derecho Constitucional se pronuncian sobre el tratamiento que la Constitución española hace del referendum. La problemática que este mecanismo de Democracia directa genera en el constitucionalismo evidencia las reticencias de los constituyentes a su generalización en nuestra vigente Carta Magna; pero a su vez expresa la necesidad o al menos conveniencia de fomentar ciertos mecanismos de referendum para posibilitar en ciertos casos una mayor y más activa participación de la ciudadanía.

KEY WORDS: referendum, direct democracy, participation, representation.

Palabras Clave: referendum, democracia directa, participación, representación. 
